Review

\title{
Updates on the Role of ABSCISIC ACID INSENSITIVE 5 (ABI5) and ABSCISIC ACID-RESPONSIVE ELEMENT BINDING FACTORs (ABFs) in ABA Signaling in Different Developmental Stages in Plants
}

\author{
Anna Collin (D), Agata Daszkowska-Golec*(D) and Iwona Szarejko \\ Institute of Biology, Biotechnology and Environmental Protection, Faculty of Natural Sciences, \\ University of Silesia in Katowice, ul. Jagiellońska 28, 40-032 Katowice, Poland; anna.skubacz@us.edu.pl (A.C.); \\ iwona.szarejko@us.edu.pl (I.S.) \\ * Correspondence: agata.daszkowska@us.edu.pl; Tel.: +48-32-2009-360
}

Citation: Collin, A.;

Daszkowska-Golec, A.; Szarejko, I. Updates on the Role of ABSCISIC ACID INSENSITIVE 5 (ABI5) and ABSCISIC ACID-RESPONSIVE ELEMENT BINDING FACTORs (ABFs) in ABA Signaling in Different Developmental Stages in Plants. Cells 2021, 10, 1996. https://doi.org/ 10.3390/cells10081996

Academic Editor:

Suleyman Allakhverdiev

Received: 7 July 2021

Accepted: 3 August 2021

Published: 5 August 2021

Publisher's Note: MDPI stays neutral with regard to jurisdictional claims in published maps and institutional affiliations.

Copyright: (c) 2021 by the authors. Licensee MDPI, Basel, Switzerland. This article is an open access article distributed under the terms and conditions of the Creative Commons Attribution (CC BY) license (https:/ / creativecommons.org/licenses/by/ $4.0 /)$.

\begin{abstract}
The core abscisic acid (ABA) signaling pathway consists of receptors, phosphatases, kinases and transcription factors, among them ABA INSENSITIVE 5 (ABI5) and ABRE BINDING FACTORs/ABRE-BINDING PROTEINs (ABFs/AREBs), which belong to the BASIC LEUCINE ZIPPER (bZIP) family and control expression of stress-responsive genes. ABI5 is mostly active in seeds and prevents germination and post-germinative growth under unfavorable conditions. The activity of ABI5 is controlled at transcriptional and protein levels, depending on numerous regulators, including components of other phytohormonal pathways. ABFs/AREBs act redundantly in regulating genes that control physiological processes in response to stress during vegetative growth. In this review, we focus on recent reports regarding ABI5 and ABFs/AREBs functions during abiotic stress responses, which seem to be partially overlapping and not restricted to one developmental stage in Arabidopsis and other species. Moreover, we point out that ABI5 and ABFs/AREBs play a crucial role in the core ABA pathway's feedback regulation. In this review, we also discuss increased stress tolerance of transgenic plants overexpressing genes encoding ABA-dependent bZIPs. Taken together, we show that ABI5 and ABFs/AREBs are crucial ABA-dependent transcription factors regulating processes essential for plant adaptation to stress at different developmental stages.
\end{abstract}

Keywords: ABI5; ABF; AREB; abiotic stress response; abscisic acid; phytohormone crosstalk

\section{Insight into the Core ABA Signaling and ABA-Dependent bZIPs Function}

Each year abiotic stresses, including drought and salinity, reduce crop yield, causing economic problems and a severe threat to food safety. Thus, it is crucial to understand plant adaptation mechanisms to unfavorable environmental conditions with aim to develop stress-tolerant cultivars [1,2]. Abscisic acid (ABA) is a significant phytohormone regulating plant responses to various abiotic stresses $[3,4]$. In response to stress, $\mathrm{ABA}$ is synthesized in plant cells triggering activation of the ABA signaling pathway. The core ABA signaling consists of ABA receptors (PYRABACTIN RESISTANCE PROTEINS/PYR-LIKE PROTEINS/REGULATORY COMPONENTS OF ABA RECEPTOR; PYR/PYL/RCAR), phosphatases (PHOSPHATASE 2Cs; PP2Cs), kinases (SNF1-RELATED PROTEIN KINASE 2; SnRK2s), and transcription factors belonging to large BASIC LEUCINE ZIPPER (bZIP) family. After perceiving the primary stress signal, ABA forms a complex with PYR/PYL/RCAR receptors and PP2C phosphatases. It prevents PP2Cs from dephosphorylating SnRK2s and releases a SnRK2s phosphorylation activity. SnRK2 kinases phosphorylate and activate bZIP transcription factors, such as ABA INSENSITIVE 5 (ABI5) and ABRE BINDING FACTORs/ABRE-BINDING PROTEINs (ABFs/AREBs) [5-7]. However, it has to be underlined that ABA-dependent bZIPs are also phosphorylated by other kinases [8-10]. Recently, it was found that RAF-LIKE KINASE 10 (RAF10) and CALCIUM-DEPENDENT PROTEIN 
KINASE 6 (CPK6) interact with ABI5 and ABFs/AREBs and phosphorylate them [11,12]. Moreover, RIBOSOMAL S6 KINASE2 (S6K2), kinase active in TARGET OF RAPAMYCIN (TOR) signaling, was also shown to bind with ABI5 what in turn stimulates ABA response and drought tolerance [13]. Phosphorylated ABI5 and ABFs/AREBs recognize ABA RESPONSIVE ELEMENTs (ABRE cis-elements) containing (C/T)ACGTGGC motif and G-box coupling elements (GCEs) with ACGT/C core sequence, present in the promoters of stressresponsive genes. These bZIP factors activate or repress their expression and trigger plant adaptation to stress $[5,14,15]$.

In our previous review [10], we described the function of AtABI5 and its homologs in the acquisition of stress tolerance in plants. However, recently numerous new data emerged about ABI5 and ABFs/AREBs function under stress. This review presents new evidence on $\mathrm{ABI} 5$ and $\mathrm{ABFs}$ / AREBs role in plant adaptation to stress and describes a tight control of their activity by other stress regulators. We also focus on ABI5 and ABFs/AREBs actions in the feedback regulation of ABA pathway and the possibility of utilizing ABA-dependent bZIPs in developing stress-tolerant cultivars.

\section{New Evidence of ABI5 Regulatory Role during Seed Germination}

In Arabidopsis thaliana, ABA-induced activation of ABI5 inhibits germination under unfavorable environmental conditions. ABI5 is responsible for the regulation of expression of stress-responsive genes, e.g., EARLY METHIONINE-LABELED 1 (EM1) and EM6 encoding LATE EMBRYOGENESIS ABUNDANT (LEA) proteins $[10,16,17]$. Recently, ABI5 was shown to repress the expression of PHOSPHATE1 (PHO1), a gene involved in phosphate (Pi) transfer from cotyledons to radicles which promotes germination. Therefore, one of the mechanisms of ABI5-dependent germination inhibition is repression of Pi transfer [18]. Furthermore, ABI5 can directly activate CATALASE 1 (CAT1), encoding a catalase responsible for scavenging $\mathrm{H}_{2} \mathrm{O}_{2}$, the main reactive oxygen species (ROS). It indicates that ABI5 is also involved in maintaining ROS homeostasis during seed germination [19] (Figure 1).

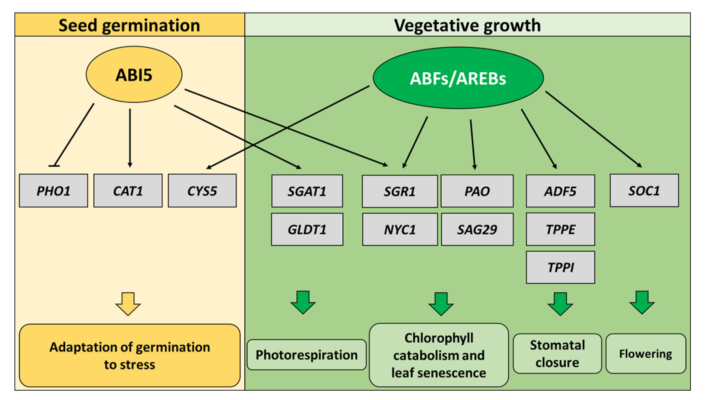

Figure 1. Partially overlapping function of ABA INSENSITIVE 5 (ABI5) and ABRE BINDING FACTORs/ABRE-BINDING PROTEINs (ABFs/AREBs). ABI5 regulates seed germination accordingly to surrounding environmental conditions. ABI5 promotes CATALASE 1 (CAT1) and represses PHOSPHATE1 (PHO1), responsible for reactive oxygen species (ROS) scavenging and phosphate transfer, respectively, during seed germination, while ABFs/AREBs ensure stress adaptation in vegetative tissues. Genes associated with chlorophyll catabolism (STAY-GREEN 1-SGR1, NON-YELLOW COLORING 1-NYC1), leaf senescence (PHEOPHORBIDE A OXYGENASE-PAO, SENESCENCEASSOCIATED GENE 29-SAG29), stomatal closure (ACTIN-DEPOLYMERIZING FACTOR 5-ADF5, TREHALOSE-6-PHOSPHATE PHOSPHATASE E-TPPE, TPPI) and flowering time (SUPPRESSOR OF OVEREXPRESSION OF CO 1-SOC1) are the direct targets of ABFs/AREBs. ABI5 is also able to promote expression of chlorophyll catabolism (SGR1, NYC1) and photorespiration (SERINE:GLYOXYLATE AMINOTRANSFERASE 1-SGAT1, GDC T-PROTEIN—GLDT1) genes in vegetative tissues, whereas ABFs / AREBs activate expression of CYSTEINE PROTEINASE INHIBITOR 5 (CYS5) in seeds.

Multiple transcription factors regulate $A B I 5$ expression during seed germination in Arabidopsis [10,20-22]. Recently, the new regulator of $A B I 5$ in seeds was identified. AGAMOUS-LIKE 21 (AGL21) belongs to MCM1 / AGAMOUS/DEFICIENS/SRF (MADS) 
box group of transcription factors. It was shown that AGL21 activates the expression of ABI5 in ABA-treated seeds in Arabidopsis [23].

In Arabidopsis, ABI5 is also regulated at the protein level. It interacts with numerous proteins, modulating its stability or activity as a transcription factor [10,24-27]. Recently, XPO1-INTERACTING WD40 PROTEIN 1 (XIW1), a member of WD40-repeat protein (WD40) family, was found to be crucial for ABI5 stability during seed germination. XIW1 shuttles between nucleus and cytoplasm dependently on environmental conditions. ABA promotes nuclear localization of XIW1. Colocalization of XIW1 and ABI5 in the nucleus leads to their physical interaction and, thus, protects ABI5 from proteasomal degradation, which enables ABA-mediated responses in seeds [28] (Figure 2). Furthermore, the interaction between ABI5 and autophagy cargo receptor, NEIGHBOUR OF BREAST CANCER 1 (NBR1), may enhance ABI5 stability and ABA response at the germination stage [29,30]. Recently, Yang et al. [31] showed that ABI5 activity is regulated by circadian clock regulators, PSEUDO-RESPONSE REGULATOR5 (PRR5) and PRR7. Both proteins interact physically with ABI5 to stimulate ABA response in seeds and to inhibit germination according to day/night cycle (Figure 2). Moreover, Pan et al. [32] discovered that ABA-induced members of the newly identified VQ motif-containing protein (VQ) family, VQ18 and VQ26, interact physically with ABI5 and block its function (Figure 2). VQ18 and VQ26 were proposed to be a part of the fine-tuning mechanism in the frame of ABA signaling during seed germination. Furthermore, ABI5 BINDING PROTEIN 2 (AFP2) was found to interact with $\mathrm{ABI} 5$ and inhibits its transactivation of SOMNUS (SOM), encoding a negative regulator of GA accumulation and seed germination under high temperature [33] (Figure 2). It is noteworthy that another AFP protein, AFP1, was shown to promote ABI5 degradation [25].

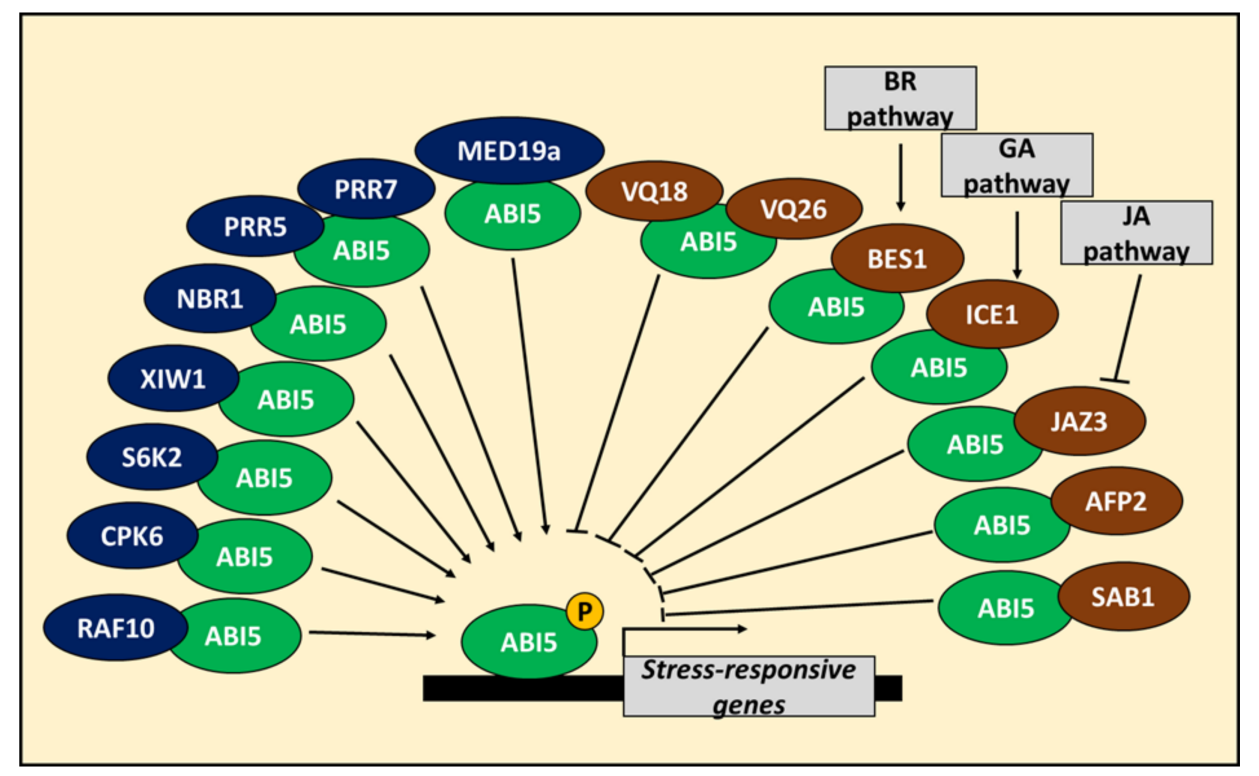

Figure 2. Positive and negative regulators of ABA INSENSITIVE 5 (ABI5) protein stability and/or function. ABI5 stability and activity is under regulation of multiple proteins. ABI5 stability and function is promoted by interaction with kinases CALCIUM-DEPENDENT PROTEIN KINASE 6 (CPK6), RAF-LIKE KINASE 10 (RAF10) and RIBOSOMAL S6 KINASE2 (S6K2), shuttle protein XPO1-INTERACTING WD40 PROTEIN 1 (XIW1), circadian clock regulators PSEUDO-RESPONSE REGULATOR 5 (PRR5) and PRR7 and mediator subunit MEDIATOR COMPLEX SUBUNIT 19a (MED19a). ABI5 is also stabilized by interaction with NEIGHBOUR OF BREAST CANCER 1 (NBR1). On the other side, ABI5 stability and/or function is negatively affected by VQ18, VQ26, BRASSINOSTEROID INSENSITIVE 1 (BRI1)-EMS-SUPPRESSOR 1 (BES1), INDUCER OF CBF EXPRESSION1 (ICE1), JASMONATE-ZIM DOMAIN PROTEIN 3 (JAZ3), ABI5 BINDING PROTEIN 2 (AFP2) and SENSITIVE TO ABA 1 (SAB1). BES1, ICE1 and JAZ3 are also involved in brassinosteroid (BR), gibberellic acid (GA) and jasmonic acid (JA) signaling, respectively. P-phosphate group. 


\section{Involvement of ABI5 in Phytohormonal Crosstalk at the Seed Germination Stage}

ABI5 can act as a hub in phytohormonal crosstalk in Arabidopsis [10,27,34-37]. The last reports confirm this hypothesis and indicate that at the seed germination stage ABI5 plays an essential role in brassinosteroid (BR), gibberellic acid (GA), cytokinin (CK) and jasmonic acid (JA) signaling through interaction with components of these pathways [38-41]. Zhao et al. [38] showed the interaction between ABI5 and BRASSINOSTEROID INSENSITIVE 1 (BRI1)-EMS-SUPPRESSOR 1 (BES1), a BR-dependent transcription factor and negative regulator of ABA signaling. BES1 inhibits ABI5 activity and thus promotes seed germination (Figure 2). Interestingly, binding of BES1 to ABI5 prevents the ABI5 interaction with ABI3, the enhancer of ABI5 transactivation function [38]. Similarly, INDUCER OF CBF EXPRESSION1 (ICE1) transcription factor binds and represses ABI5 transactivation function in seeds. This interaction is promoted by GA, but inhibited by DELLA proteins, negative components of GA signaling, which also bind to ICE1 and therefore restore ABA signaling and ABI5 function [39]. Furthermore, CK-dependent regulators ARABIDOPSIS RESPONSE REGULATOR 4 (ARR4), ARR5 and ARR6 inhibit ABI5 expression at germination stage [42], whereas other components of CK signaling, ARABIDOPSIS HISTIDINE KINASE 4 (AHK4), ARABIDOPSIS HISTIDINE PHOSPHOTRANSFER PROTEIN 2 (AHP2), AHP3, AHP5 and ARR12 trigger ABI5 protein degradation during cotyledon greening [36]. Moreover, JASMONATE-ZIM DOMAIN PROTEIN 3 (JAZ3), a negative regulator of JA response, interacts with $\mathrm{ABI} 5$ and reduces its activity as transcription factor in germinating seeds (Figure 2). However, ABA treatment promotes JAZ3 degradation and JA biosynthesis in the ABI5-dependent way [40]. Recently, it was shown that JAZ proteins repress $A B I 3$ and $A B I 5$ expression, while JA stimulates $A B A$ response through regulation of $A B I 3$ and $A B I 5$ during seed germination inhibition [41].

\section{The Function and Regulation of ABI5 during Seedling Development}

ABI5 plays the essential role in repression of seedling growth under osmotic, salt and cold stress in Arabidopsis [10,43,44]. It was recently found that ABI5 may also be essential for seedling growth tolerance to aluminum (Al) through expression regulation of genes related to cell wall modification and osmoregulation [45]. New evidence also emerged about $A B I 5$ transcriptional regulation in Arabidopsis seedlings. It was shown that NAM/ATAF1/2/CUC2 (NAC) transcription factor, ANAC060, represses ABI5 activity in seedlings in response to glucose. Interesting, it can be a part of negative feedback regulation between $\mathrm{ABI} 5$ and another $\mathrm{ABA}$-dependent and glucose-related transcription factor, ABI4, which promotes ANAC060 expression [46]. Previously, B-BOX DOMAIN PROTEIN 21 (BBX21) was shown to inhibit the $A B I 5$ expression under light [47]. Kang et al. [48] revealed that $\mathrm{BBX} 21$ represses $A B I 5$ by recruiting its promoter chromatin modifier, HYPERSENSITIVE TO RED AND BLUE 2/PICKLE (HRB2/PKL). Decreased ABI5 expression results in maintenance of stomatal aperture at the level that is necessary for gas exchange, however, the precise mechanism is unknown. Therefore, these data indirectly indicate that ABI5 is responsible for the regulation of stomata movement in seedlings [48]. In the dark, ABI5 expression is activated by PHYTOCHROME-INTERACTING FACTORs (PIF): PIF1, PIF3, PIF4 and PIF5 that are the negative regulators of photomorphogenesis [49]. Interestingly, previously ABI5 was shown to interact with PIF1 to strengthen its function as a transcription factor [50]. WRKY18, WRKY40 and WRKY60 are negative regulators of ABI5 transcription in seedlings [10,51]. Recently, WRKY40 was found to recruit a histone 3 lysine 4 (H3K4) demethylase JUMONJI DOMAIN-CONTAINING PROTEIN 17 (JMJ17) to chromatin of $A B I 5$ gene. JMJ17 removes marks of transcriptionally active chromatin (H3K4me3) from $A B I 5$ and thus also inhibits $A B I 5$ expression at epigenetic level in seedlings under non-stressed conditions [52].

Other proteins also modulate ABI5 activity during seedling development in Arabidopsis. Similar to seeds, ABI5 stability is regulated by XIW1 and NBR1 at the seedling stage $[28,29]$. Furthermore, MEDIATOR COMPLEX SUBUNIT 19a (MED19a) physically interacts with ABI5 during ABA-dependent inhibition of root growth and cotyledon green- 
ing (Figure 2). It was shown that MED19a strengthens ABI5 binding to the promoters of EM1 and EM6 [53]. It has to be underlined that ABI5 is negatively regulated by another MEDIATOR subunit, MED25 [10,35]. The next identified ABI5 interactor, SENSITIVE TO ABA 1 (SAB1), in many ways inhibits ABI5 activity during early seedling growth. SAB1 belongs to REGULATOR OF CHROMATIN CONDENSATION 1 (RCC1) family and it binds to ABI5 serine at 145 position, which serves as a target of SnRK2s-mediated phosphorylation. The SAB1 binding causes reduction of ABI5 phosphorylation status and leads to its degradation (Figure 2). SAB1 also binds to ABI5 promoter and inhibits ABI5 to auto-activate its expression. Moreover, SAB1 increases the level of histone H3K27me2, the epigenetic mark of expression repression, in the $A B I 5$ promoter [54]. Together, all these findings show that ABI5 activity undergoes complex and strict regulation, which shows that ABI5 plays an essential role in ABA signaling during early developmental stages. It has to be pointed out that ABI5 can interact with other transcription factors to regulate their activity. ABI5 is involved in anthocyanin accumulation in seedlings [44]. Recently, it was shown that in apple (Malus domestica), homolog of AtABI5, MdABI5, binds with basic helix-loop-helix 3 (MdbHLH3) which in turn enhances expression of its target genes, DIHYDROFLAVONOL 4-REDUCTASE (MdDFR) and UDP FLAVONOID GLUCOSYL TRANSFERASE (MdUF3GT), involved in anthocyanin biosynthesis. Moreover, MdABI5 strengthens interaction between MdbHLH3 and MdMYB1, another transcription factor involved in anthocyanin biosynthesis. MdABI5 can also promote directly expression of MdbHLH3 [55].

\section{Redundant Function of ABFs/AREBs in the Regulation of Plant Stress Responses in Vegetative Tissues}

ABFs/AREBs: ABF1, ABF2/AREB1, ABF4/AREB2, and ABF3 regulate plant response to abiotic stresses, such as drought, salt, heat, oxidative stress, and cold, mostly in vegetative tissues of Arabidopsis [56-59]. ABFs/AREBs ensure the adaptation to unfavorable environmental conditions via promoting expression of $L E A$ genes, such as RESPONSIVE TO DESSCICATION 29B (RD29B), RESPONSIVE TO ABA 18 (RAB18), COLD-RESPONSIVE 6.6 (COR6.6/KIN2), and regulatory genes, such as DEHYDRATION-RESPONSIVE ELEMENT BINDING PROTEIN 2A (DREB2A) [14,57,60]. However, ABFs/AREBs role in ABA-mediated adaptation to stress is highly redundant. Quadruple mutant abf2/areb1 $a b f 4 / a r e b 2 a b f 3 a b f 1$ showed a significantly lower survival rate after drought treatment than single abf/areb mutants. Similar observations were made for the primary root growth of abf/areb mutants in the presence of ABA [14,61]. Moreover, ABFs / AREBs can interact with each other and function together to regulate expression of target genes $[8,14]$. On the other side, $\mathrm{ABF} 2 / \mathrm{AREB} 1, \mathrm{ABF} 4 / \mathrm{AREB} 2$, and ABF3 regulate the expression of $R D 29 B$ or $R A B 18$ in a slightly different way, which indicates the partially independent role of each $A B F / A R E B$ during adaptation to stress [14].

$A B F S / A R E B s$ regulate redundantly also stomatal closure in Arabidopsis. ACTINDEPOLYMERIZING FACTOR 5 (ADF5) encodes a protein responsible for actin cytoskeleton remodeling during stomatal closure in response to ABA. ABF1, ABF2/AREB1, ABF4/AREB2 and $\mathrm{ABF} 3$ bind to $A D F 5$ promoter, activate its expression, promote stomatal closure and ensure adaptation to drought [15]. It was recently shown that ABFs/AREBs-mediated stomatal closure depends on accumulation of disaccharide trehalose in seedlings. ABF1, ABF2/AREB1 and ABF4/AREB2 directly bind to the promoter of TREHALOSE-6-PHOSPHATE PHOSPHATASE I (TPPI) and promote its expression. TPPI gene encodes the trehalose biosynthesis enzyme [62]. Additionally, ABF2/AREB1 directly activates another gene from TPP family, TPPE [63] (Figure 1). Strikingly, TPPI is involved in promoting primary root growth, whereas TPPE takes part in ABA-dependent inhibition of root growth $[62,63]$. Homologs of AtABF / AREB in other dicot species are also involved in stomata regulation. In cotton (Gossypium hirsutum), GhABF2D promotes stomatal closure and thus abiotic stress tolerance [64]. Moreover, carrot (Daucus carota) DcABF3 activates expression of genes involved in stomata development, SPEECHLESS (SPCH), FAMA (FMA) and MUTE, which in turn increases number of stomata [65]. 
In vegetative tissues of Arabidopsis, $\mathrm{ABFs} / \mathrm{AREBs}$ are regulated at transcriptional, post-transcriptional and protein levels. Expression of $A B F S / A R E B s$ is under control of other stress-responsive transcription factors, NACs. NAC016 and NAC-LIKE, ACTIVATED BY $\mathrm{AP} 3 / \mathrm{PI}$ (NAP) were shown to repress $A B F 2 / A R E B 1$ under drought [66]. Additionally, NAP negatively regulates also salt stress response by inhibiting $A B F 2 / A R E B 1$ [67]. Furthermore, $A B F 3$ expression can be downregulated at the post-transcriptional level by miR399f to release ABA-mediated growth arrest under stress [68]. ABFs/AREBs activity is also modulated by NACs at the protein level. Previously, ABF2/AREB1 and ABF4/AREB2 were found to bind with ANAC096 and cooperatively regulate the expression of stress-responsive genes [69]. Interestingly, the NAC072 interacts with ABF3 to enhance expression of RD29A and to decrease $R D 29 B$ activity. Therefore, NAC072 exerts a differential type of action on ABF3 function in ABA signaling [70]. Recently, the activity of ABF2/AREB1 was shown to be likely enhanced by interaction with GA-related DELLA proteins. This could promote stomatal closure and drought tolerance. It was evidenced that the ABF2/AREB1 was also involved in ABA-GA crosstalk to ensure the efficient response to drought stress [71].

\section{The Partially Overlapping Function of ABI5 and ABFs/AREBs in Seeds, Seedlings, and Vegetative Tissues}

Although ABI5 is considered as the main ABA-dependent bZIP factor regulating stress responses in seeds and seedlings, $\mathrm{ABFs} / \mathrm{AREB}$ s also seem to be active during Arabidopsis' early developmental stages. The function of ABFs / AREBs during germination and early seedling development was already indicated by Kim et al. [72], Finkelstein et al. [73] and Sharma et al. [59]. They observed faster germination of $a b f 1, a b f 4 / a r e b 2$ and $a b f 3$ mutants under optimal growth conditions and better germination rate of $a b f 4 / a r e b 2$ and $a b f 3$ under ABA treatment $[59,72]$. Moreover, ABF3 acts redundantly with ABI5 in seeds and during post-germinative growth under abiotic stress [73]. It was also shown that ABF3 directly promotes $A B I 5$ expression in salt-treated seedlings [74]. Furthermore, ABF3 together with $\mathrm{ABF} 1$ regulate seed germination and post-germinative growth under heat stress. They directly activate expression of CYSTEINE PROTEINASE INHIBITOR 5 (CYS5), a gene encoding an inhibitor of cysteine protease, leading to thermotolerant germination and growth of primary root [75] (Figure 1). $A B F 1, A B F 3$ and $A B F 4 / A R E B 2$ also regulate seed germination under salt and osmotic stress, downstream of DE-ETIOLATED 1 (DET1), a negative regulator involved in light signaling pathway [76].

On the other side, ABI5 is active in vegetative tissues of Arabidopsis. Recently, You et al. [77] showed that ABI5 takes part in the adaptation of plant growth to a low $\mathrm{CO}_{2}$ level [78]. It was noted that ABI5 binds to the promoters of SERINE:GLYOXYLATE AMINOTRANSFERASE 1 (SGAT1) and GDC T-PROTEIN (GLDT1) genes encoding enzymes associated with photorespiration process, and activates their expression [77] (Figure 1). Moreover, ABI5 is important for regulation of plant juvenile-to-adult transition. In response to ABA, MYB33, the main target of miR159, directly activates ABI5 transcription. Next, ABI5 influences positively on MIR156 expression, what in turn delays vegetative development under abiotic stress [79]. Furthermore, function of ABI5 and ABFs/AREBs can be overlapping in vegetative tissues. It has to be underlined that ABI5 can form heterodimers with ABFs/AREBs, which is the evidence of their synergistic role in ABA responses [8]. ABI5 was shown to inhibit photosynthesis and promote chlorophyll catabolism and leaf senescence [10,80,81] (Figure 1). However, ABFs / AREBs are also involved in regulating ABA-induced chlorophyll catabolism and leaf senescence in a similar way. ABF2/AREB1, ABF4/AREB2 and ABF3 directly activate expression of genes associated with chlorophyll catabolism: STAY-GREEN 1/NON-YELLOWING 1 (SGR1/NYE1), PHEOPHORBIDE A OXYGENASE (PAO), NON-YELLOW COLORING 1 (NYC1), and leaf senescence, SENESCENCEASSOCIATED GENE 29 (SAG29) [82] (Figure 1). Besides Arabidopsis, ABI5 function was also observed during inhibition of chloroplast-related processes in potato (Solanum tuberosum). Similar to AtABI5, StABI5 negatively impacts photosynthesis and promotes chlorophyll catabolism and leaf senescence via positive regulation of CHLOROPLAST VESICULATION (StCV) and StNYC1, encoding proteins involved in chlorophyll degra- 
dation [83]. Moreover, in apple MdABI5 binds directly to promoters of MdNYE1 and $M d N Y C 1$ to promote chlorophyll catabolism and leaf senescence. MdABI5 transcriptional activity during regulation of leaf senescence is enhanced by its physical interaction with MdWRKY40 and MdbZIP44, but weakened by binding with MdBBX22 [84]. On the other side, dicot AtABF / AREB homologs, tomato (Solanum lycopersicum) SlAREB1 and sweetpotato (Ipomoea batatas) IbABF4 positively regulate photosynthesis efficiency in response to stress $[85,86]$.

In vegetative tissues $\mathrm{ABI} 5$ can be also involved in response to biotic stress. $A B I 5$ expression is under epigenetic control of HOOKLESS1 (HLS1), which takes part in plant response to pathogens. It might imply that ABI5 is related to plant defense reaction against biotic stress [87]. Recently, it was shown that in tobacco (Nicotiana benthamiana), homolog of AtABI5, NbABI5 is able to directly repress the gene responsible for chloroplast electron transfer chain, FERREDOXIN 1 (NbFD1), in rice stripe virus (RSV)-infected tobacco plants. NbFD1 is also involved in callose deposition in plasmodesmata, which in turn protects plant against viral infection. Therefore, RSV-mediated activation of NbABI5 can inhibit plant defense mechanism to virus [88]. It should be also underlined that tomato SlAREB1 participates in regulation of biotic stress-responsive genes such as PATHOGENESIS-RELATED GENE 5 (PR5) or CHITINASE3 (CHI3) [85]. Together, all these observations indicate that function of $A B I 5$ and $A B F s / A R E B s$ is not only restricted to seed germination and vegetative tissues, respectively. Furthermore, $A B I 5$ can function synergistically with $A B F s / A R E B s$ during ABA-dependent responses.

\section{The Role of ABI5 and ABFs/AREBs in Flowering Regulation and Fruit Ripening}

In Arabidopsis, ABFs/AREBs and ABI5 take part in ABA-dependent regulation of flowering timing. ABF4/AREB2 and ABF3 were shown to regulate flowering time and mediate the drought-escape mechanism. Both ABFs/AREBs interact with NUCLEAR FACTOR Y, SUBUNITs C3/4/9 (NF-YC3/4/9) in the promoter of SUPPRESSOR OF OVEREXPRESSION OF CO 1 (SOC1), to promote its expression. SOC1 encodes a MADS box transcription factor, an important regulator of flowering timing. ABA-induced expression of SOC1 accelerates flowering under drought [89] (Figure 1). Moreover, Xiong et al. [90] observed that $A B I 5$ undergoes regulation at the post-transcriptional level during flowering transition. In the presence of ABA, splicing regulator, U2AF65b, increases efficiency of intron splicing from $A B I 5$ pre-mRNA, which promotes abundance of $A B I 5$ mature transcripts. This type of the $A B I 5$ expression control was observed in a shoot apex during ABA-mediated regulation of flowering transition [90].

Recently, some evidence emerged that ABI5 and ABFs/AREBs are also involved in fruit ripening and have an effect on fruit quality [91]. In Japanese plum (Prunus salicina), PsABI5 can directly activate the expression of ethylene biosynthesis gene, ACC SYNTHASE1 (PSACS1) and thus, it takes part in fruit maturation [92]. It was also found that expression of MdABI5 in apple is directly activated by KNOTTED1-LIKE HOMEOBOX 19 (MdKNOX19), ABA-responsive transcription factor involved in inhibition of fruit and seed development [93]. Additionally, apple MdAREB2 promotes accumulation of soluble sugars through regulation of expression of sugar transporter (SUCROSE TRANSPORTER 2, MdSUT2 and TONOPLAST MONOSACCHARIDE TRANSPORTER1, MdTMT1) and $\alpha$-/ $\beta$-amylase (MdAMY1, MdAMY3, MdBAM1 and MdBAM3) genes, which in turn affects fruit quality [94]. Moreover, MaABI5, a banana homolog of AtABI5, is associated with ABA-induced cold tolerance of banana (Musa acuminata) fruits [95].

\section{Function of ABI5 and ABFs/AREBs Homologs in Monocots}

In monocots, a function of ABI5 and ABFs/AREBs homologs is usually not restricted to the specific developmental stage as it is observed in Arabidopsis. Monocot homologs of AtABI5 can be active in seeds and vegetative tissues during ABA-dependent responses to abiotic stress [10,96-99]. It was observed that rice (Oryza sativa) OsABI5, OsABF1, OsABF2/ABI5-Like1 (OsABL1)/OsbZIP46, OsABF4/OsbZIP72, OsTRAB1, wheat 
(Triticum aestivum) TaABL1, ABRE BINDING PROTEIN 1 (TaABP1), TaAREB3, wABI5 and maize (Zea mays) ZmABP9, ZmABI5 are crucial components of abiotic stress responses in vegetative tissues because of ABA-dependent regulation of stress-responsive genes [97-108]. Moreover, barley (Hordeum vulgare) HvABI5, rice OsABF2/OsABL1/OsbZIP46, OsABF4/OsbZIP72 and maize ZmABP9 regulate ABA-dependent responses at seed germination stage [96,103,105-107]. Furthermore, another monocot ABI5 and ABFs/AREBs homologs, barley HvABF1, HvABF2, sorghum (Sorghum bicolor) SbABI5 and wheat TaABF1, are important for ABA-GA crosstalk during seed germination [109-112] (Table 1).

Table 1. Function of $A B I 5$ and $A B F s / A R E B s$ homologs in monocots.

\begin{tabular}{|c|c|c|c|c|}
\hline Name & Source & $\begin{array}{l}\text { GenBank ID/Ensembl } \\
\text { Plants ID }\end{array}$ & Function & References \\
\hline$H v A B F 1$ & Hordeum vulgare & $\begin{array}{c}\text { DQ786408/ } \\
\text { HORVU3Hr1G084360 }\end{array}$ & $\begin{array}{l}\text { Inhibition of GA-induced expression of } A m y 32 b \text { in } \\
\text { aleurone cells }\end{array}$ & [110] \\
\hline$H v A B F 2$ & Hordeum vulgare & $\begin{array}{c}\text { DQ786409/ } \\
\text { HORVU7Hr1G035500 }\end{array}$ & $\begin{array}{l}\text { Inhibition of GA-induced expression of } A m y 32 b \text { in } \\
\text { aleurone cells }\end{array}$ & [110] \\
\hline \multirow{3}{*}{$H v A B I 5$} & \multirow{3}{*}{ Hordeum vulgare } & $\begin{array}{c}\text { AY150676/ } \\
\text { HORVU5Hr1G068230 }\end{array}$ & $\begin{array}{l}\text { ABA-dependent activation of HVA1 and HVA22 in } \\
\text { aleurone cells }\end{array}$ & [96] \\
\hline & & $\begin{array}{c}\text { AY150676/ } \\
\text { HORVU5Hr1G068230 }\end{array}$ & Direct activation of $H v C A T 2$ in dormant seeds & [113] \\
\hline & & $\begin{array}{l}\text { HQ456390/ } \\
\text { HORVU5Hr1G068230 }\end{array}$ & $\begin{array}{l}\text { ABA-dependent regulation of drought response } \\
\text { including stomatal closure, flavonoid biosynthesis, } \\
\text { photosynthesis inhibition and activation of } \\
\text { stress-responsive and ABA pathway genes, regulation } \\
\text { of seed germination under ABA }\end{array}$ & [114] \\
\hline OsABF1 & Oryza sativa & $\begin{array}{l}\text { GQ904238/ } \\
\text { Os01t0867300 }\end{array}$ & $\begin{array}{l}\text { Positive regulation of drought and salt stress responses } \\
\text { through activation of stress-responsive genes }\end{array}$ & [104] \\
\hline $\begin{array}{l}\text { OsABF2/ } \\
\text { OsABL1/ } \\
\text { OsbZIP46 }\end{array}$ & Oryza sativa & $\begin{array}{l}\text { GU552783, } \\
\text { XM_015785510/ } \\
\text { Os06t0211200 }\end{array}$ & $\begin{array}{c}\text { Positive regulation of drought, salt and oxidative stress } \\
\text { responses, ABA-dependent regulation of } \\
\text { stress-responsive genes including } W R K Y s, \\
\text { participation in auxin responses, regulation of seed } \\
\text { germination under ABA }\end{array}$ & {$[105,106,115]$} \\
\hline $\begin{array}{l}\text { OsABF4/ } \\
\text { OsbZIP72 }\end{array}$ & Oryza sativa & $\begin{array}{c}\text { AK065873, } \\
\text { XM_015757064/ } \\
\text { Os09g0456200 }\end{array}$ & $\begin{array}{l}\text { Positive regulation of drought response, regulation of } \\
\text { seed germination under ABA, activation of chlorophyll } \\
\text { catabolism genes: OsSGR1 and OsNYC1 }\end{array}$ & {$[103,116]$} \\
\hline \multirow[t]{2}{*}{ OsABI5 } & \multirow[t]{2}{*}{ Oryza sativa } & \multirow[t]{2}{*}{$\begin{array}{l}\text { EF199631/ } \\
\text { Os01t0859300 }\end{array}$} & $\begin{array}{l}\text { Negative regulation of drought and salt stress } \\
\text { responses, involved in expression regulation of } \\
\text { stress-responsive genes and in pollen maturation }\end{array}$ & [97] \\
\hline & & & Interaction with OsKEAP1 at seed germination stage & {$[117]$} \\
\hline OsTRAB1 & Oryza sativa & $\begin{array}{c}\mathrm{AB} 023288 / \\
\text { Os08t0472000 }\end{array}$ & ABA-dependent regulation of stress-responsive genes & [102] \\
\hline SbABI5 & Sorghum bicolor & $\begin{array}{l}\text { XM_002454559/ } \\
\text { SORBI_3004G309600 }\end{array}$ & $\begin{array}{l}\text { Activation of GA catabolism gene } S b G A 2 o x 3 \text { in } \\
\text { embryos and promotion of seed dormancy }\end{array}$ & {$[111,118]$} \\
\hline TaABF1 & $\begin{array}{l}\text { Triticum } \\
\text { aestivum }\end{array}$ & $\begin{array}{c}\text { AF519804/ } \\
\text { TraesCS3A02G371800 }\end{array}$ & $\begin{array}{l}\text { Inhibition of GA-induced expression of } A m y 32 b \text { in } \\
\text { aleurone cells via repression of } G A M y b \text { expression }\end{array}$ & {$[109,112]$} \\
\hline TaABP1 & $\begin{array}{l}\text { Triticum } \\
\text { aestivum }\end{array}$ & $\begin{array}{c}\text { HQ166718/ } \\
\text { TraesCS3B02G404300 }\end{array}$ & Positive regulation of drought response & [108] \\
\hline
\end{tabular}


Table 1. Cont.

\begin{tabular}{|c|c|c|c|c|}
\hline Name & Source & $\begin{array}{l}\text { GenBank ID/Ensembl } \\
\text { Plants ID }\end{array}$ & Function & References \\
\hline \multirow{2}{*}{ TaABI5 } & \multirow{2}{*}{$\begin{array}{l}\text { Triticum } \\
\text { aestivum }\end{array}$} & \multirow{2}{*}{$\begin{array}{c}\text { AB238932/ } \\
\text { TraesCS3D02G364900 }\end{array}$} & $\begin{array}{l}\text { Interaction with TaJAZ1, a negative regulator of JA signaling, } \\
\text { at seed germination stage }\end{array}$ & {$[40]$} \\
\hline & & & $\begin{array}{l}\text { Regulation of seed dormancy and germination under } \mathrm{ABA} \text {, } \\
\text { activation of } L E A \text { expression }\end{array}$ & [119] \\
\hline TaABL1 & $\begin{array}{l}\text { Triticum } \\
\text { aestivum }\end{array}$ & $\begin{array}{c}\text { BJ267580/ } \\
\text { TraesCS6A02G333600 }\end{array}$ & $\begin{array}{l}\text { Positive regulation of drought, salt, freezing and oxidative } \\
\text { stresses responses through promotion of chlorophyll } \\
\text { accumulation, stomatal closure and stress-responsive genes } \\
\text { expression, regulation of seed germination under ABA }\end{array}$ & [100] \\
\hline TaAREB3 & $\begin{array}{l}\text { Triticum } \\
\text { aestivum }\end{array}$ & - & $\begin{array}{l}\text { Positive regulation of drought response through activation of } \\
\text { stress-responsive genes }\end{array}$ & [101] \\
\hline$w A B I 5$ & $\begin{array}{l}\text { Triticum } \\
\text { aestivum }\end{array}$ & $\begin{array}{c}\text { AB193553/ } \\
\text { TraesCS5A02G237200 }\end{array}$ & $\begin{array}{l}\text { Positive regulation of drought, salt and freezing stresses } \\
\text { responses through activation of stress-responsive genes }\end{array}$ & [98] \\
\hline $\mathrm{ZmABP9}$ & Zea mays & $\begin{array}{c}\text { GU237073/ } \\
\text { Zm00001eb147240 }\end{array}$ & $\begin{array}{l}\text { Positive regulation of drought, salt, freezing and oxidative } \\
\text { stresses responses through promotion of photosynthesis, } \\
\text { stomatal closure, ROS scavenging and stress-responsive } \\
\text { genes expression; regulation of seed germination under ABA; } \\
\text { direct activation of ZmCAT1 }\end{array}$ & [107] \\
\hline \multirow[t]{2}{*}{$\mathrm{ZmABI5}$} & \multirow[t]{2}{*}{ Zea mays } & \multirow[t]{2}{*}{$\begin{array}{c}\text { EU968937/ } \\
\text { Zm00001d018178 }\end{array}$} & $\begin{array}{l}\text { Negative regulation of drought, salt, heat and cold stresses } \\
\text { responses through promotion of chlorophyll catabolism and } \\
\text { inhibition of detoxifying enzymes activity and proline } \\
\text { accumulation, regulation of stress-responsive genes }\end{array}$ & [99] \\
\hline & & & Activation of raffinose biosynthesis gene, ZmGOLS2, in seeds & [120] \\
\hline
\end{tabular}

Recently, a set of new data has emerged regarding monocot AtABI5 and AtABFs/AREBs homologs. Ishibashi et al. [113] found that HvABI5, similarly to AtABI5, directly activates expression of $\mathrm{HvCAT2}$ and thus reduces $\mathrm{H}_{2} \mathrm{O}_{2}$ level in embryos and promotes seed dormancy. HvABI5 was also described as an ABA-dependent regulator of drought response in barley vegetative tissues via participation in stomatal closure, photosynthesis inhibition and flavonoid accumulation. It has to be underlined that HvABI5 enables drought adaptation by activation of stress-responsive genes and the induction of genes encoding core ABA pathway components [114]. Furthermore, Zhang et al. [120] found that $Z m A B I 5$ is active in seeds and the encoded transcription factor directly promotes GALACTINOL SYNTHASE2 (ZmGOLS2) gene expression associated with raffinose biosynthesis, which is essential for seed viability. Therefore, HvABI5 and ZmABI5 expression regulate $A B A-d e p e n d e n t$ responses during seed germination and further developmental stages. However, in wheat, TaABI5 was shown to be active only in seeds. It promotes $L E A$ expression and maintains seeds in dormancy stage. Transgenic Arabidopsis lines overexpressing TaABI5 were ABA-hypersensitive during seed germination [119,121]. Furthermore, as observed in Arabidopsis, TaJAZ1 is able to interact with TaABI5 and thus it inhibits ABA-dependent TaABI5 activity and promotes seed germination [40]. Similar activity of TaABI5 and AtABI5 indicates that TaABI5 can be a functional ortholog of AtABI5 in wheat. Piao et al. [116] found that OsABF4/OsbZIP72 is involved in chlorophyll catabolism and leaf senescence, such as it was observed for AtABI5 and AtABFs/AREBs. They showed that OsABF4/OsbZIP72 binds to promoters of genes responsible for chlorophyll catabolism, OsSGR1 and OsNYC1, and activates their expression. Moreover, OsABI5 was shown to interact with KELCH-LIKE ECH-ASSOCIATED PROTEIN 1 (OsKEAP1) which in turn promotes OsABI5 proteasomal degradation in germinating seeds under non-stressed conditions [117]. To summarize, all these findings indicate that function of monocot ABA-dependent bZIPs under abiotic stress can be diversified. It might be more or less similar to their homologs in Arabidopsis (Table 1). However, it should be noted that monocot homologs of ABI5 and ABF/AREBs can be active at different developmen- 
tal stages, whereas in dicot species their function is generally observed during specific timing. On the other side, some evidence has emerged about the role of dicot ABI5 and $\mathrm{ABF} / \mathrm{AREB}$ in ABA signaling during later developmental stages e.g., flowering, fruit development and during plant response to biotic stress. These findings have not yet been confirmed for ABI5 and ABF/AREBs in monocot species. It should be also pointed out that dicot $\mathrm{ABI} 5$ and $\mathrm{ABF} / \mathrm{AREB}$ positively regulate response to abiotic stress, whereas monocot $\mathrm{ABI} 5$ and $\mathrm{ABF} / \mathrm{AREB}$ homologs can function as positive or negative regulators of stress response. Moreover, AtABI5 plays the important role in crosstalk between ABA and other phytohormonal pathways at germination stage. This function of ABI5 has not yet been fully revealed in monocot species. Therefore, further studies are needed to reveal their proper function under stress at different developmental stages.

\section{Role of ABI5 and ABFs/AREBs in Feedback Regulation of Core ABA Pathway}

Recently, growing evidence indicated the crucial role of ABI5 and ABFs/AREBs in the feedback regulation of the core ABA signaling and ABA biosynthesis. In Arabidopsis, Wang et al. [122] found that $A B I 1$ and $A B I 2$, genes encoding group A PP2C phosphatases, negative regulators of ABA signaling, are directly activated by ABI5, ABF1, ABF2/AREB1, $\mathrm{ABF} 4 / \mathrm{AREB} 2$ and ABF3 in the presence of ABA (Figure 3). Moreover, they noticed that $A B F 2 / A R E B 1$ is a target gene of $\mathrm{ABF} 1$ and $\mathrm{ABF} 4 / \mathrm{AREB} 2$. It shows that ABA-dependent bZIPs are part of the negative feedback loop in the ABA signaling. However, they can also strengthen their expression. Recently, ABI5 was described as a direct activator of genes encoding ABA receptors, PYL11, and PYL12, during seed germination under ABA (Figure 3). Furthermore, the pattern of eight other PYL genes' expression is disturbed in abi5 mutant [123]. Thus, ABI5 is also crucial for the reinforcement of ABA signaling. Moreover, the ABA pathway's feedback regulation depends on intermediate regulators such as FYVE DOMAIN PROTEIN REQUIRED FOR ENDOSOMAL SORTING 1 (FREE1/FYVE1). FYVE1 encodes a protein localized in the peripheral membrane of late endosomal compartments and is involved in protein sorting. The expression of FYVE1 is directly induced by ABF4/AREB2 [124] (Figure 3). However, FYVE1 protein interacts with all PYR/PYL/RCAR receptors and stimulates their degradation [124,125]. Moreover, SnRK2 kinases, SnRK2.2 and SnRK2.3, which mostly phosphorylate and activate ABI5 and ABF/ AREBs, are also able to phosphorylate FYVE1 promoting its nuclear localization in response to ABA. In the nucleus, FYVE1 binds with ABI5 and ABF4/AREB2 and reduces their transactivation function [126]. Thus, ABF4/AREB2 is also involved in negative modulation of ABA-mediated stress responses through FYVE1 regulation.

Similar interactions were also observed in other species. The overexpression of StABI5 induces expression of $P Y R / P Y L / R C A R$ and $S n R K 2$ genes in potato [83]. Furthermore, it was shown in barley that expression of HvSnRK2.1, HvPP2C4 and key ABA biosynthesis gene, CAROTENOID CLEAVAGE DIOXYGENASE 1 (HvNCED1), is activated in hvabi5 mutant, which presumably exhibits enhanced activity of HvABI5 protein. HvSnRK2.1, $\mathrm{HvPP} 2 \mathrm{C} 4$, and HvNCED1 are putative ABI5 direct target genes because of ABRE elements in their promoters [114]. It is noteworthy that rice ABA-related bZIP transcription factor, OsbZIP23, can promote directly the expression of OsPP2C49 and OsNCED4 [127]. Taken together, $\mathrm{ABI} 5$ and ABFs/AREBs act in the feedback regulation of ABA pathway, which is important for the fine-tuning of ABA-dependent responses, according to the surrounding environmental conditions. 


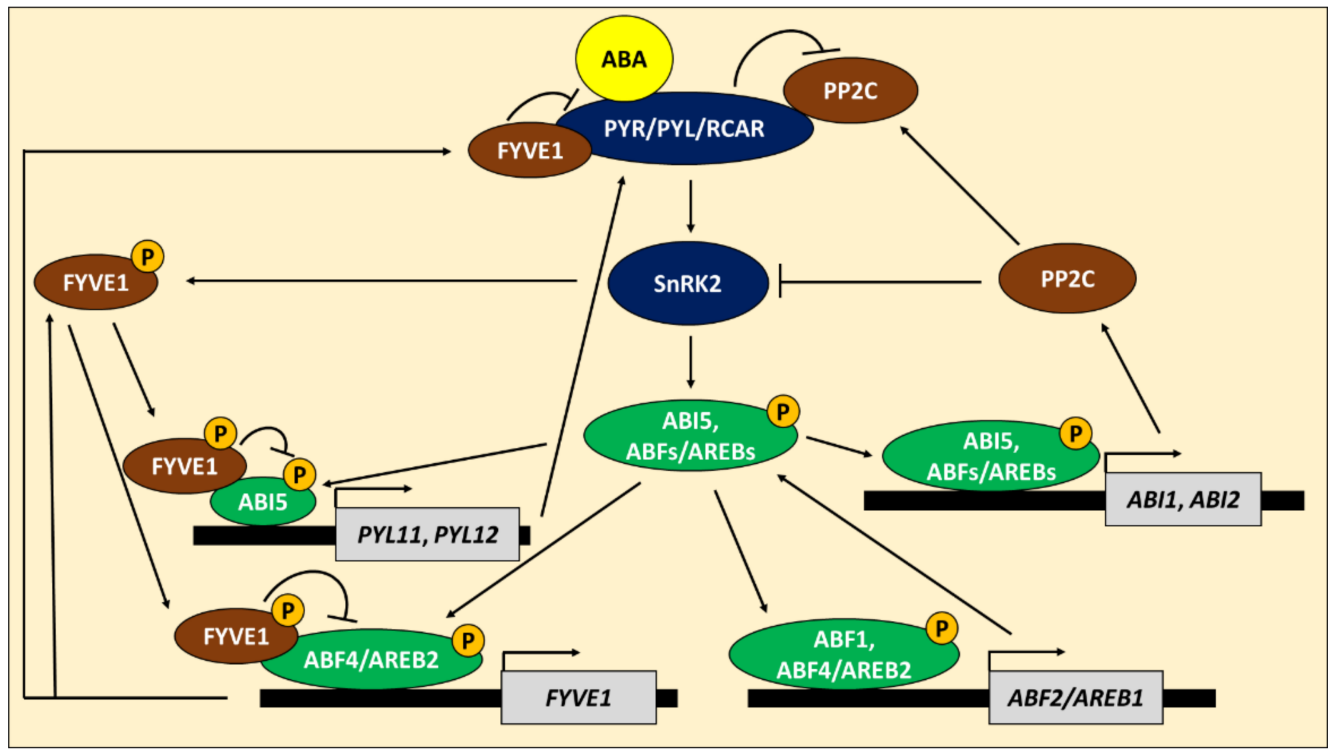

Figure 3. ABA INSENSITIVE 5 (ABI5) and ABRE BINDING FACTORs/ABRE-BINDING PROTEINs (ABFs/AREBs) function in feedback regulation of abscisic acid (ABA) pathway in Arabidopsis. In the presence of ABA, ABA receptors PYRABACTIN RESISTANCE PROTEINS/PYR-LIKE PROTEINS/REGULATORY COMPONENTS OF ABA RECEPTORs (PYR/PYL/RCARs) bind and inhibit phosphatases PHOSPHATASE 2Cs (PP2Cs), what in turn activates kinases, SNF1-RELATED PROTEIN KINASE 2s (SnRK2s). SnRK2s phosphorylate and activate ABI5 and ABFs / AREBs. Phosphatases PP2Cs, when not bound with ABA receptors PYR/PYL/RCAR, inhibit SnRK2s activity and thus ABI5 and ABFs/AREBs function. ABI5 is able to promote expression of PYL11 and PYL12 genes, which in turn strengthen ABA perception through PYR/PYL/RCAR receptors. ABF1 and ABF4/AREB2 trigger ABF2/AREB1 expression. On the other side, ABI5 and ABFs/AREBs activate expression of $A B I 1$ and $A B I 2$, genes encoding PP2Cs, which inhibits activity of SnRK2. Furthermore, ABF4/AREB2 promotes FYVE DOMAIN PROTEIN REQUIRED FOR ENDOSOMAL SORTING 1 (FYVE1) expression. FYVE1 positively regulates degradation of PYR/PYL/RCARs and diminishes ABF4/AREB2 and ABI5 activity. Inhibition of ABF4/AREB2 and ABI5 activity by FYVE1 is possible after its phosphorylation carried out by SnRK2s. P-phosphate group.

\section{Stress Tolerance of Transgenic Plants Overexpressing ABA-Dependent bZIPs}

In Arabidopsis, transgenic lines overexpressing ABFs/AREBs showed increased tolerance to multiple abiotic stresses [57,72,128,129]. Moreover, rice, soybean (Glycine max) and cotton overexpressing Arabidopsis $A B F 3, A B F 2 / A R E B 1$ and $A B I 5$, respectively, exhibited stress-tolerant phenotypes [130-132]. Therefore, ectopic expression of ABFs/AREBs, ABI5 and their homologues can serve as a biotechnological tool for developing stress-tolerant cultivars. It was recently shown that potato overexpressing $A B F 4 / A R E B 2$ was more tolerant to drought and salt stress. Plants with constitutive $A B F 4 / A R E B 2$ expression accumulated more proline and exhibited decreased stomatal conductance and transpiration rate. Furthermore, tuber yield of transgenic lines was better than the wild-type, both, in the presence of optimal growth conditions and under stress [133]. In cotton, the overexpression of At $A B F 3$ and its cotton homolog, $G h A B F 2 D$, resulted in drought tolerance related to the faster stomatal closure and reduced transpiration. However, transgenic lines also showed photosynthesis inhibition under drought [64]. Ectopic expression of $A B F 3$ also ensured increased tolerance of alfalfa (Medicago sativa) to drought, salt and oxidative stress. Drought tolerance of $A B F 3$ overexpression lines was caused by the reduction in transpiration rate, decreased ROS accumulation and higher chlorophyll content. On the other side, leaves of transgenic lines showed reduced size under optimal growth conditions [134]. The observed growth retardation could arise from constitutive expression of $A B F s / A R E B s$. However, the application of stress-inducible or tissue-specific promoters can help to avoid this problem [64,72,129]. Na and Metzger [135] obtained transgenic plants of tomato and tobacco 
(Nicotiana tabacum) overexpressing ABF4/AREB2 only in guard-cells of stomata. Transgenic lines showed reduced transpiration and ensured drought tolerance. Utilization of a guard-cell specific promoter reduced negative effect of $A B F 4 / A R E B 2$ overexpression on plant development (Table 2).

Table 2. Abiotic stress tolerance of transgenic plants overexpressing ABFs/AREBs and their homologs, generated in recent years.

\begin{tabular}{|c|c|c|c|c|}
\hline Gene & Source & Target Species & Effect & Reference \\
\hline$A B F 3$ & Arabidopsis thaliana & Medicago sativa & $\begin{array}{l}\text { Tolerance to drought, salt and oxidative stresses. } \\
\text { Reduced transpiration rate, ROS content and } \\
\text { higher chlorophyll content under stress. Smaller } \\
\text { leaf area under optimal growth conditions. }\end{array}$ & [134] \\
\hline$A B F 3$ & Arabidopsis thaliana & Gossypium hirsutum & $\begin{array}{l}\text { Tolerance to drought. Reduced transpiration and } \\
\text { photosynthetic rates. Slower growth and smaller } \\
\text { leaves under optimal growth conditions. }\end{array}$ & {$[64]$} \\
\hline ABF4/AREB2 & Arabidopsis thaliana & Solanum tuberosum & $\begin{array}{l}\text { Tolerance to drought and salt stress. Lower } \\
\text { transpiration rate and higher proline content } \\
\text { under stress. Improved tuber yield under optimal } \\
\text { growth conditions and under stress. }\end{array}$ & [133] \\
\hline$A B F 4 / A R E B 2$ & Arabidopsis thaliana & $\begin{array}{l}\text { Nicotiana tabacum and } \\
\text { Solanum lycopersicum }\end{array}$ & $\begin{array}{l}\text { Tolerance to drought. Reduced transpiration } \\
\text { under stress. Mild growth reduction under } \\
\text { optimal growth conditions. }\end{array}$ & [135] \\
\hline BnaABF2 & Brassica napus & Arabidopsis thaliana & $\begin{array}{c}\text { Tolerance to drought and salt. Reduced stomatal } \\
\text { aperture and water loss under stress. Induced } \\
\text { expression of } L E A \text { genes under stress. }\end{array}$ & [136] \\
\hline GhABF2D & Gossypium hirsutum & Gossypium hirsutum & $\begin{array}{l}\text { Tolerance to drought. Reduced transpiration and } \\
\text { photosynthetic rates. Slower growth under } \\
\text { optimal growth conditions. }\end{array}$ & {$[64]$} \\
\hline$I b A B F 4$ & Ipomoea batatas & $\begin{array}{l}\text { Arabidopsis thalianal } \\
\text { Ipomoea batatas }\end{array}$ & $\begin{array}{l}\text { Tolerance to drought, salt and oxidative stresses. } \\
\text { Higher photosynthetic efficiency, endogenous } \\
\text { ABA content and lower ROS content under stress. } \\
\text { Induced expression of } L E A \text { genes under stress. } \\
\text { Better seed germination under salt and osmotic } \\
\text { stress in Arabidopsis. }\end{array}$ & [86] \\
\hline TaAREB3 & Triticum aestivum & Arabidopsis thaliana & $\begin{array}{l}\text { Tolerance to drought and freezing stresses. Lower } \\
\text { ion leakage under stress. Induced expression of } \\
\text { LEA genes under stress. }\end{array}$ & [101] \\
\hline$V v A B F 2$ & Vitis vinifera & Arabidopsis thaliana & $\begin{array}{l}\text { Tolerance to osmotic stress. Higher activity of } \\
\text { detoxifying enzymes activity and better ROS } \\
\text { scavenging under stress. Induced expression of } \\
\text { LEA genes under stress. }\end{array}$ & [137] \\
\hline$Z m A B P 9$ & Zea mays & Gossypium hirsutum & $\begin{array}{l}\text { Tolerance to drought, salt and oxidative stresses. } \\
\text { Higher chlorophyll, proline and soluble sugars } \\
\text { content, higher activity of detoxifying enzymes, } \\
\text { reduced stomatal aperture and ROS } \\
\text { accumulation under stress, induced expression of } \\
\text { stress-responsive genes. Better seed germination } \\
\text { under salt and osmotic stress. }\end{array}$ & [138] \\
\hline
\end{tabular}

Transgenic plants overexpressing homologs of $A B I 5$ and $A B F s / A R E B s$ from other species than Arabidopsis also showed better performance under stress [98,100,103,107,108,115]. Overexpression of wheat TaAREB3 in Arabidopsis induced $L E A$ expression and conferred freezing and drought tolerance [101]. Transfer of rapeseed (Brassica napus) gene, BnaABF2, to Arabidopsis ensured better tolerance to drought and salt due to the smaller stomatal aperture and induced expression of LEAs: RD29B, RAB18 and KIN2 [136]. Overexpression 
of maize ZmABP9 in cotton resulted in tolerance to drought, salt and oxidative stresses. Transgenic lines showed a higher chlorophyll, proline and soluble sugars content, increased detoxifying enzymes activity, decreased ROS level and reduced stomatal aperture in response to stress. They also exhibited increased expression of stress-responsive genes under stress. Furthermore, seeds of transgenic lines germinated better under salt and osmotic stress [138]. Expression of $V v A B F 2$ from grapevine (Vitis vinifera) in Arabidopsis caused increased activity of detoxifying enzymes, better ability to scavenge ROS and higher $L E A$ expression. Together, it conferred tolerance to osmotic stress of transgenic lines [137]. Moreover, overexpression of sweet potato IbABF4 in Arabidopsis and in sweet potato ensured tolerance to drought, salt and oxidative stresses, and lower ROS level, elevated ABA content, better performance of photosynthesis, and higher expression of $L E A$ genes associated with stress. Additionally, Arabidopsis transgenic lines showed better germination rate under salt and osmotic stress [86] (Table 2).

Together, these data show that ABA-dependent bZIPs are a promising tool for developing cultivars with enhanced tolerance to abiotic stresses. However, the activity of ABA-dependent bZIPs can depend on a target species, type of applied stress and analyzed developmental stage. Moreover, overexpression of $A B F s / A R E B s$ and their homologs can also cause undesirable growth retardation under optimal conditions. Thus, laborious preliminary studies are needed before utilizing ABA-dependent bZIPs for obtaining stress-tolerant crops.

\section{Concluding Remarks}

ABA-dependent regulation of plant response to abiotic stress involves the activity of many different components. ABA-dependent bZIPs, ABI5 and ABFs/AREBs are a group of transcription factors that trigger plant adaptation to unfavorable stress conditions. Their activity is strictly controlled by multiple regulators at transcriptional and protein level to ensure the accurate response to surrounding environmental conditions. In Arabidopsis, $\mathrm{ABI} 5$ and $\mathrm{ABFs} / \mathrm{AREBs}$ are mostly active in seeds and in vegetative tissues, respectively. However, very often their function is overlapping and together, in response to ABA, they regulate many processes including seed germination, chlorophyll catabolism and flowering time. In monocots, ABI5 and ABFs/AREBs homologs are involved in regulation of stress responses, however, their activity is usually observed during different developmental stages. Function of ABI5 and ABFs/AREBs is also crucial for the feedback regulation of core ABA pathway, which results in promotion or repression of ABA-dependent plant response to the stress. Finally, ABI5, ABFs/AREBs and their homologs can serve as candidates for developing transgenic plants with increased tolerance to abiotic stress. However, more studies are necessary to understand the precise function of numerous ABA-dependent bZIPs in regulation of plant responses to multiple abiotic stresses at different developmental stages.

Author Contributions: A.C. wrote the manuscript and prepared figures. A.D.-G. and I.S. contributed to the writing of manuscript and revised it critically for important intellectual content. All authors have read and agreed to the published version of the manuscript.

Funding: This work was supported by the National Science Centre, Poland, project PRELUDIUM 2017/25/N/NZ9/01941 “The role of HvABI5 transcription factor in spring barley (Hordeum vulgare L.) response to drought stress".

Institutional Review Board Statement: Not applicable.

Informed Consent Statement: Not applicable.

Data Availability Statement: Not applicable.

Conflicts of Interest: The authors declare no conflict of interest. 


\section{References}

1. Mahmood, T.; Khalid, S.; Abdullah, M.; Ahmed, Z.; Shah, M.K.N.; Ghafoor, A.; Du, X. Insights into Drought Stress Signaling in Plants and the Molecular Genetic Basis of Cotton Drought Tolerance. Cells 2019, 9, 105. [CrossRef] [PubMed]

2. Blum, A. Towards a conceptual ABA ideotype in plant breeding for water limited environments. Funct. Plant Biol. 2015, 42, 502-513. [CrossRef]

3. Sah, S.K.; Reddy, K.R.; Li, J. Abscisic acid and abiotic stress tolerance in crop plants. Front. Plant Sci. 2016, 7, 571. [CrossRef] [PubMed]

4. Martignago, D.; Rico-Medina, A.; Blasco-Escámez, D.; Fontanet-Manzaneque, J.B.; Caño-Delgado, A.I. Drought Resistance by Engineering Plant Tissue-Specific Responses. Front. Plant Sci. 2020, 10, 1676. [CrossRef] [PubMed]

5. Banerjee, A.; Roychoudhury, A. Abscisic-acid-dependent basic leucine zipper (bZIP) transcription factors in plant abiotic stress. Protoplasma 2017, 254, 3-16. [CrossRef]

6. Dejonghe, W.; Okamoto, M.; Cutler, S.R. Small molecule probes of ABA biosynthesis and signaling. Plant Cell Physiol. 2018, 59, 1490-1499. [CrossRef]

7. Yoshida, T.; Christmann, A.; Yamaguchi-Shinozaki, K.; Grill, E.; Fernie, A.R. Revisiting the Basal Role of ABA—Roles Outside of Stress. Trends Plant Sci. 2019, 24, 625-635. [CrossRef]

8. Lynch, T.; Erickson, B.J.; Finkelstein, R.R. Direct interactions of ABA-insensitive(ABI)-clade protein phosphatase(PP)2Cs with calcium-dependent protein kinases and ABA response element-binding bZIPs may contribute to turning off ABA response. Plant Mol. Biol. 2012, 80, 647-658. [CrossRef] [PubMed]

9. Zhou, X.; Hao, H.; Zhang, Y.; Bai, Y.; Zhu, W.; Qin, Y.; Yuan, F.; Zhao, F.; Wang, M.; Hu, J.; et al. SOS2-LIKE PROTEIN KINASE5, an SNF1-RELATED PROTEIN KINASE3-Type protein kinase, is important for abscisic acid responses in arabidopsis through phosphorylation of ABSCISIC ACID-INSENSITIVE5. Plant Physiol. 2015, 168, 659-676. [CrossRef]

10. Skubacz, A.; Daszkowska-Golec, A.; Szarejko, I. The role and regulation of ABI5 (ABA-insensitive 5) in plant development, abiotic stress responses and phytohormone crosstalk. Front. Plant Sci. 2016, 7, 1884. [CrossRef] [PubMed]

11. Nguyen, Q.T.C.; Lee, S.J.; Choi, S.W.; Na, Y.J.; Song, M.R.; Hoang, Q.T.N.; Sim, S.Y.; Kim, M.S.; Kim, J.I.; Soh, M.S.; et al. Arabidopsis Raf-Like Kinase Raf10 Is a Regulatory Component of Core ABA Signaling. Mol. Cells 2019, 42, 646-660. [CrossRef] [PubMed]

12. Zhang, H.; Liu, D.; Yang, B.; Liu, W.Z.; Mu, B.; Song, H.; Chen, B.; Li, Y.; Ren, D.; Deng, H.; et al. Arabidopsis CPK6 positively regulates $\mathrm{ABA}$ signaling and drought tolerance through phosphorylating ABA-responsive element-binding factors. J. Exp. Bot. 2020, 71, 188-203. [CrossRef]

13. Li, L.; Zhu, T.; Song, Y.; Feng, L.; Farag, E.A.H.; Ren, M. ABSCISIC ACID INSENSITIVE5 Interacts With RIBOSOMAL S6 KINASE2 to Mediate ABA Responses During Seedling Growth in Arabidopsis. Front. Plant Sci. 2021, 11, 598654. [CrossRef]

14. Yoshida, T.; Fujita, Y.; Sayama, H.; Kidokoro, S.; Maruyama, K.; Mizoi, J.; Shinozaki, K.; Yamaguchi-Shinozaki, K. AREB1, AREB2, and ABF3 are master transcription factors that cooperatively regulate ABRE-dependent ABA signaling involved in drought stress tolerance and require ABA for full activation. Plant J. 2010, 61, 672-685. [CrossRef] [PubMed]

15. Qian, D.; Zhang, Z.; He, J.; Zhang, P.; Ou, X.; Li, T.; Niu, L.; Nan, Q.; Niu, Y.; He, W.; et al. Arabidopsis ADF5 promotes stomatal closure by regulating actin cytoskeleton remodeling in response to ABA and drought stress. J. Exp. Bot. 2019, 70, 435-446. [CrossRef] [PubMed]

16. Finkelstein, R.R.; Lynch, T.J. The Arabidopsis abscisic acid response gene ABI5 encodes a basic leucine zipper transcription factor. Plant Cell 2000, 12, 599-609. [CrossRef]

17. Carles, C.; Bies-Etheve, N.; Aspart, L.; Léon-Kloosterziel, K.M.; Koornneef, M.; Echeverria, M.; Delseny, M. Regulation of Arabidopsis thaliana Em genes: Role of ABI5. Plant J. 2002, 30, 373-383. [CrossRef] [PubMed]

18. Huang, Y.; Sun, M.M.; Ye, Q.; Wu, X.Q.; Wu, W.H.; Chen, Y.F. Abscisic acid modulates seed germination via ABA INSENSITIVE5mediated PHOSPHATE1. Plant Physiol. 2017, 175, 1661-1668. [CrossRef]

19. Bi, C.; Ma, Y.; Wu, Z.; Yu, Y.T.; Liang, S.; Lu, K.; Wang, X.F. Arabidopsis ABI5 plays a role in regulating ROS homeostasis by activating CATALASE 1 transcription in seed germination. Plant Mol. Biol. 2017, 94, 197-213. [CrossRef] [PubMed]

20. Chen, C.; Wu, C.; Miao, J.; Lei, Y.; Zhao, D.; Sun, D.; Yang, G.; Huang, J.; Zheng, C. Arabidopsis SAG protein containing the MDN1 domain participates in seed germination and seedling development by negatively regulating ABI3 and ABI5. J. Exp. Bot. 2014, 65, 35-45. [CrossRef]

21. Feng, C.Z.; Chen, Y.; Wang, C.; Kong, Y.H.; Wu, W.H.; Chen, Y.F. Arabidopsis RAV1 transcription factor, phosphorylated by SnRK2 kinases, regulates the expression of ABI3, ABI4, and ABI5 during seed germination and early seedling development. Plant J. 2014, 80, 654-668. [CrossRef]

22. Dekkers, B.J.W.; He, H.; Hanson, J.; Willems, L.A.J.; Jamar, D.C.L.; Cueff, G.; Rajjou, L.; Hilhorst, H.W.M.; Bentsink, L. The Arabidopsis Delay of Germination 1 gene affects Abscisic Acid Insensitive 5 (ABI5) expression and genetically interacts with ABI3 during Arabidopsis seed development. Plant J. 2016, 85, 451-465. [CrossRef]

23. Yu, L.H.; Wu, J.; Zhang, Z.S.; Miao, Z.Q.; Zhao, P.X.; Wang, Z.; Xiang, C. Bin Arabidopsis MADS-Box Transcription Factor AGL21 Acts as Environmental Surveillance of Seed Germination by Regulating ABI5 Expression. Mol. Plant 2017, 10, 834-845. [CrossRef]

24. Nakamura, S.; Lynch, T.J.; Finkelstein, R.R. Physical interactions between ABA response loci of Arabidopsis. Plant J. 2001, 26, 627-635. [CrossRef]

25. Lopez-Molina, L.; Mongrand, S.; Kinoshita, N.; Chua, N.H. AFP is a novel negative regulator of ABA signaling that promotes ABI5 protein degradation. Genes Dev. 2003, 17, 410-418. [CrossRef] 
26. Stone, S.L.; Williams, L.A.; Farmer, L.M.; Vierstra, R.D.; Callis, J. KEEP ON GOING, a RING E3 ligase essential for Arabidopsis growth and development, is involved in abscisic acid signaling. Plant Cell 2006, 18, 3415-3428. [CrossRef] [PubMed]

27. $\mathrm{Hu}, \mathrm{Y}$; Yu, D. BRASSINOSTEROID INSENSITIVE2 Interacts with ABSCISIC ACID INSENSITIVE5 to Mediate the Antagonism of Brassinosteroids to Abscisic Acid during Seed Germination in Arabidopsis. Plant Cell 2014, 26, 4394-4408. [CrossRef] [PubMed]

28. Xu, X.; Wan, W.; Jiang, G.; Xi, Y.; Huang, H.; Cai, J.; Chang, Y.; Duan, C.G.; Mangrauthia, S.K.; Peng, X.; et al. Nucleocytoplasmic Trafficking of the Arabidopsis WD40 Repeat Protein XIW1 Regulates ABI5 Stability and Abscisic Acid Responses. Mol. Plant 2019, 12, 1598-1611. [CrossRef] [PubMed]

29. Tarnowski, L.; Rodriguez, M.C.; Brzywczy, J.; Piecho-Kabacik, M.; Krčkova, Z.; Martinec, J.; Wawrzynska, A.; Sirko, A. A selective autophagy cargo receptor NBR1 modulates abscisic acid signalling in Arabidopsis thaliana. Sci. Rep. 2020, 10, 7778. [CrossRef] [PubMed]

30. Zhang, Y.; Chen, Z. Broad and Complex Roles of NBR1-Mediated Selective Autophagy in Plant Stress Responses. Cells 2020, 9, 2562. [CrossRef]

31. Yang, M.; Han, X.; Yang, J.; Jiang, Y.; Hu, Y. The Arabidopsis circadian clock protein PRR5 interacts with and stimulates ABI5 to modulate abscisic acid signaling during seed germination. Plant Cell 2021, koab168. [CrossRef] [PubMed]

32. Pan, J.; Wang, H.; Hu, Y.; Yu, D. Arabidopsis vq18 and vq26 proteins interact with abi5 transcription factor to negatively modulate aba response during seed germination. Plant J. 2018, 95, 529-544. [CrossRef]

33. Chang, G.; Wang, C.; Kong, X.; Chen, Q.; Yang, Y.; Hu, X. AFP2 as the novel regulator breaks high-temperature-induced seeds secondary dormancy through ABI5 and SOM in Arabidopsis thaliana. Biochem. Biophys. Res. Commun. 2018, 501, 232-238. [CrossRef]

34. Piskurewicz, U.; Jikumaru, Y.; Kinoshita, N.; Nambara, E.; Kamiya, Y.; Lopez-Molina, L. The gibberellic acid signaling repressor RGL2 inhibits Arabidopsis seed germination by stimulating abscisic acid synthesis and ABI5 activity. Plant Cell 2008, 20, 2729-2745. [CrossRef]

35. Chen, R.; Jiang, H.; Li, L.; Zhai, Q.; Qi, L.; Zhou, W.; Liu, X.; Li, H.; Zheng, W.; Sun, J.; et al. The Arabidopsis Mediator Subunit MED25 Differentially Regulates Jasmonate and Abscisic Acid Signaling through Interacting with the MYC2 and ABI5 Transcription Factors. Plant Cell 2012, 24, 2898-2916. [CrossRef]

36. Guan, C.; Wang, X.; Feng, J.; Hong, S.; Liang, Y.; Ren, B.; Zuo, J. Cytokinin antagonizes abscisic acid-mediated inhibition of cotyledon greening by promoting the degradation of ABSCISIC ACID INSENSITIVE5 protein in Arabidopsis. Plant Physiol. 2014, 164, 1515-1526. [CrossRef] [PubMed]

37. Yuan, T.-T.; Xu, H.-H.; Zhang, K.-X.; Guo, T.-T.; Lu, Y.-T. Glucose inhibits root meristem growth via ABA INSENSITIVE 5, which represses PIN1 accumulation and auxin activity in Arabidopsis. Plant Cell Environ. 2014, 37, 1338-1350. [CrossRef] [PubMed]

38. Zhao, X.; Dou, L.; Gong, Z.; Wang, X.; Mao, T. BES1 hinders ABSCISIC ACID INSENSITIVE5 and promotes seed germination in Arabidopsis. New Phytol. 2019, 221, 908-918. [CrossRef]

39. Hu, Y.; Han, X.; Yang, M.; Zhang, M.; Pan, J.; Yu, D. The transcription factor INDUCER OF CBF EXPRESSION1 interacts with ABSCISIC ACID INSENSITIVE5 and DELLA proteins to fine-tune abscisic acid signaling during seed germination in arabidopsis. Plant Cell 2019, 31, 1520-1538. [CrossRef] [PubMed]

40. Ju, L.; Jing, Y.; Shi, P.; Liu, J.; Chen, J.; Yan, J.; Chu, J.; Chen, K.M.; Sun, J. JAZ proteins modulate seed germination through interaction with ABI5 in bread wheat and Arabidopsis. New Phytol. 2019, 223, 246-260. [CrossRef] [PubMed]

41. Pan, J.; Hu, Y.; Wang, H.; Guo, Q.; Chen, Y.; Howe, G.A.; Yu, D. Molecular mechanism underlying the synergetic effect of jasmonate on abscisic acid signaling during seed germination in arabidopsis. Plant Cell 2020, 32, 3846-3865. [CrossRef] [PubMed]

42. Wang, Y.; Li, L.; Ye, T.; Zhao, S.; Liu, Z.; Feng, Y.Q.; Wu, Y. Cytokinin antagonizes ABA suppression to seed germination of Arabidopsis by downregulating ABI5 expression. Plant J. 2011, 68, 249-261. [CrossRef]

43. Lopez-Molina, L.; Mongrand, S.; Chua, N.H. A postgermination developmental arrest checkpoint is mediated by abscisic acid and requires the ABI5 transcription factor in Arabidopsis. Proc. Natl. Acad. Sci. USA 2001, 98, 4782-4787. [CrossRef] [PubMed]

44. Brocard, I.M.; Lynch, T.J.; Finkelstein, R.R. Regulation and Role of the Arabidopsis Abscisic Acid-Insensitive 5 Gene in Abscisic Acid, Sugar, and Stress Response. Plant Physiol. 2002, 129, 1533-1543. [CrossRef] [PubMed]

45. Fan, W.; Xu, J.M.; Wu, P.; Yang, Z.X.; Lou, H.Q.; Chen, W.W.; Jin, J.F.; Zheng, S.J.; Yang, J.L. Alleviation by abscisic acid of Al toxicity in rice bean is not associated with citrate efflux but depends on ABI5-mediated signal transduction pathways. J. Integr. Plant Biol. 2019, 61, 140-154. [CrossRef] [PubMed]

46. Yu, B.; Wang, Y.; Zhou, H.; Li, P.; Liu, C.; Chen, S.; Peng, Y.; Zhang, Y.; Teng, S. Genome-wide binding analysis reveals that ANAC060 directly represses sugar-induced transcription of ABI5 in Arabidopsis. Plant J. 2020, 103, 965-979. [CrossRef]

47. Xu, D.; Li, J.; Gangappa, S.N.; Hettiarachchi, C.; Lin, F. Convergence of Light and ABA Signaling on the ABI5 Promoter. PLoS Genet. 2014, 10, e1004197. [CrossRef]

48. Kang, X.; Xu, G.; Lee, B.; Chen, C.; Zhang, H.; Kuang, R.; Ni, M. HRB2 and BBX21 interaction modulates Arabidopsis ABI5 locus and stomatal aperture. Plant Cell Environ. 2018, 41, 1912-1925. [CrossRef]

49. Qi, L.; Liu, S.; Li, C.; Fu, J.; Jing, Y.; Cheng, J.; Li, H.; Zhang, D.; Wang, X.; Dong, X.; et al. PHYTOCHROME-INTERACTING FACTORS Interact with the ABA Receptors PYL8 and PYL9 to Orchestrate ABA Signaling in Darkness. Mol. Plant 2020, 13, 414-430. [CrossRef]

50. Kim, J.; Kang, H.; Park, J.; Kim, W.; Yoo, J.; Lee, N.; Kim, J.; Yoon, T.Y.; Choi, G. PIF1-interacting transcription factors and their binding sequence elements determine the in vivo targeting sites of PIF1. Plant Cell 2016, 28, 1388-1405. [CrossRef] 
51. Liu, Z.Q.; Yan, L.; Wu, Z.; Mei, C.; Lu, K.; Yu, Y.T.; Liang, S.; Zhang, X.F.; Wang, X.F.; Zhang, D. Cooperation of three WRKYdomain transcription factors WRKY18, WRKY40, and WRKY60 in repressing two ABA-responsive genes ABI4 and ABI5 in Arabidopsis. J. Exp. Bot. 2012, 63, 6371-6392. [CrossRef]

52. Wang, T.J.; Huang, S.; Zhang, A.; Guo, P.; Liu, Y.; Xu, C.; Cong, W.; Liu, B.; Xu, Z.Y. JMJ17-WRKY40 and HY5-ABI5 modules regulate the expression of ABA-responsive genes in Arabidopsis. New Phytol. 2021, 230, 567-584. [CrossRef]

53. Li, X.; Yang, R.; Gong, Y.; Chen, H. The Arabidopsis Mediator Complex Subunit MED19a is Involved in ABI5-mediated ABA Responses. J. Plant Biol. 2018, 61, 97-110. [CrossRef]

54. Ji, H.; Wang, S.; Cheng, C.; Li, R.; Wang, Z.; Jenkins, G.I.; Kong, F.; Li, X. The RCC1 family protein SAB1 negatively regulates ABI5 through multidimensional mechanisms during postgermination in Arabidopsis. New Phytol. 2019, 222, 907-922. [CrossRef]

55. An, J.P.; Zhang, X.W.; Liu, Y.J.; Wang, X.F.; You, C.X.; Hao, Y.J. ABI5 regulates ABA-induced anthocyanin biosynthesis by modulating the MYB1-bHLH3 complex in apple. J. Exp. Bot. 2021, 72, 1460-1472. [CrossRef] [PubMed]

56. Choi, H.I.; Hong, J.H.; Ha, J.O.; Kang, J.Y.; Kim, S.Y. ABFs, a family of ABA-responsive element binding factors. J. Biol. Chem. 2000, 275, 1723-1730. [CrossRef] [PubMed]

57. Fujita, Y.; Fujita, M.; Satoh, R.; Maruyama, K.; Parvez, M.M.; Seki, M.; Hiratsu, K.; Ohme-Takagi, M.; Shinozaki, K.; YamaguchiShinozaki, K. AREB1 is a transcription activator of novel ABRE-dependent ABA signaling that enhances drought stress tolerance in Arabidopsis. Plant Cell 2005, 17, 3470-3488. [CrossRef] [PubMed]

58. Abdeen, A.; Schnell, J.; Miki, B. Transcriptome analysis reveals absence of unintended effects in drought-tolerant transgenic plants overexpressing the transcription factor ABF3. BMC Genom. 2010, 11, 69. [CrossRef]

59. Sharma, P.D.; Singh, N.; Ahuja, P.S.; Reddy, T.V. Abscisic acid response element binding factor 1 is required for establishment of Arabidopsis seedlings during winter. Mol. Biol. Rep. 2011, 38, 5147-5159. [CrossRef] [PubMed]

60. Kim, J.S.; Mizoi, J.; Yoshida, T.; Fujita, Y.; Nakajima, J.; Ohori, T.; Todaka, D.; Nakashima, K.; Hirayama, T.; Shinozaki, K.; et al. An ABRE promoter sequence is involved in osmotic stress-responsive expression of the DREB2A gene, which encodes a transcription factor regulating drought-inducible genes in Arabidopsis. Plant Cell Physiol. 2011, 52, 2136-2146. [CrossRef]

61. Yoshida, T.; Fujita, Y.; Maruyama, K.; Mogami, J.; Todaka, D.; Shinozaki, K.; Yamaguchi-Shinozaki, K. Four Arabidopsis AREB/ABF transcription factors function predominantly in gene expression downstream of SnRK2 kinases in abscisic acid signalling in response to osmotic stress. Plant Cell Environ. 2015, 38, 35-49. [CrossRef]

62. Lin, Q.; Wang, S.; Dao, Y.; Wang, J.; Wang, K. Arabidopsis thaliana trehalose-6-phosphate phosphatase gene TPPI enhances drought tolerance by regulating stomatal apertures. J. Exp. Bot. 2020, 71, 4285-4297. [CrossRef]

63. Wang, W.; Chen, Q.; Xu, S.; Liu, W.C.; Zhu, X.; Song, C.P. Trehalose-6-phosphate phosphatase E modulates ABA-controlled root growth and stomatal movement in Arabidopsis. J. Integr. Plant Biol. 2020, 62, 1518-1534. [CrossRef]

64. Kerr, T.C.C.; Abdel-Mageed, H.; Aleman, L.; Lee, J.; Payton, P.; Cryer, D.; Allen, R.D. Ectopic expression of two AREB/ABF orthologs increases drought tolerance in cotton (Gossypium hirsutum). Plant Cell Environ. 2018, 41, 898-907. [CrossRef] [PubMed]

65. Wang, Y.H.; Que, F.; Li, T.; Zhang, R.R.; Khadr, A.; Xu, Z.S.; Tian, Y.S.; Xiong, A.S. DcABF3, an ABF transcription factor from carrot, alters stomatal density and reduces ABA sensitivity in transgenic Arabidopsis. Plant Sci. 2021, 302, 110699. [CrossRef] [PubMed]

66. Sakuraba, Y.; Kim, Y.S.; Han, S.H.; Lee, B.D.; Paek, N.C. The arabidopsis transcription factor NAC016 promotes drought stress responses by repressing AREB1 transcription through a trifurcate feed-forward regulatory loop involving NAP. Plant Cell 2015, 27, 1771-1787. [CrossRef] [PubMed]

67. Seok, H.Y.; Woo, D.H.; Nguyen, L.V.; Tran, H.T.; Tarte, V.N.; Mehdi, S.M.M.; Lee, S.Y.; Moon, Y.H. Arabidopsis AtNAP functions as a negative regulator via repression of AREB1 in salt stress response. Planta 2017, 245, 329-341. [CrossRef]

68. Baek, D.; Chun, H.J.; Kang, S.; Shin, G.; Park, S.J.; Hong, H.; Kim, C.; Kim, D.H.; Lee, S.Y.; Kim, M.C.; et al. A role for arabidopsis miR399f in salt, drought, and ABA signaling. Mol. Cells 2016, 39, 111-118. [CrossRef]

69. Xu, Z.Y.; Kim, S.Y.; Hyeon, D.Y.; Kim, D.H.; Dong, T.; Park, Y.; Jin, J.B.; Joo, S.H.; Kim, S.K.; Hong, J.C.; et al. The Arabidopsis NAC transcription factor ANAC096 cooperates with bZIP-type transcription factors in dehydration and osmotic stress responses. Plant Cell 2013, 25, 4708-4724. [CrossRef]

70. Li, X.; Li, X.; Li, M.; Yan, Y.; Liu, X.; Li, L. Dual function of NAC072 in ABF3-mediated ABA-responsive gene regulation in Arabidopsis. Front. Plant Sci. 2016, 7, 1075. [CrossRef]

71. Wang, Z.; Liu, L.; Cheng, C.; Ren, Z.; Xu, S.; Li, X. GAI functions in the plant response to dehydration stress in Arabidopsis thaliana. Int. J. Mol. Sci. 2020, 21, 819. [CrossRef] [PubMed]

72. Kim, S.; Kang, J.Y.; Cho, D.I.; Park, J.H.; Soo, Y.K. ABF2, an ABRE-binding bZIP factor, is an essential component of glucose signaling and its overexpression affects multiple stress tolerance. Plant J. 2004, 40, 75-87. [CrossRef] [PubMed]

73. Finkelstein, R.; Gampala, S.S.L.; Lynch, T.J.; Thomas, T.L.; Rock, C.D. Redundant and distinct functions of the ABA response loci ABA-insensitive(ABI)5 and ABRE-binding factor (ABF)3. Plant Mol. Biol. 2005, 59, 253-267. [CrossRef] [PubMed]

74. Chang, H.C.; Tsai, M.C.; Wu, S.S.; Chang, I.F. Regulation of ABI5 expression by ABF3 during salt stress responses in Arabidopsis thaliana. Bot. Stud. 2019, 60, 16. [CrossRef]

75. Song, C.; Kim, T.; Chung, W.S.; Lim, C.O. The Arabidopsis phytocystatin AtCYS5 enhances seed germination and seedling growth under heat stress conditions. Mol. Cells 2017, 40, 577-586. [CrossRef]

76. Fernando, V.C.D.; Al Khateeb, W.; Belmonte, M.F.; Schroeder, D.F. Role of Arabidopsis ABF1/3/4 during det1 germination in salt and osmotic stress conditions. Plant Mol. Biol. 2018, 97, 149-163. [CrossRef] [PubMed] 
77. You, L.; Zhang, J.; Li, L.; Xiao, C.; Feng, X.; Chen, S.; Guo, L.; Hu, H. Involvement of abscisic acid, ABI5, and PPC2 in plant acclimation to low CO2. J. Exp. Bot. 2020, 71, 4093-4108. [CrossRef] [PubMed]

78. Sunil, B.; Saini, D.; Bapatla, R.B.; Aswani, V.; Raghavendra, A.S. Photorespiration is complemented by cyclic electron flow and the alternative oxidase pathway to optimize photosynthesis and protect against abiotic stress. Photosynth. Res. 2019, 139, 67-79. [CrossRef]

79. Guo, C.; Jiang, Y.; Shi, M.; Wu, X.; Wu, G. ABI5 acts downstream of miR159 to delay vegetative phase change in Arabidopsis. New Phytol. 2021, 231, 339-350. [CrossRef]

80. Sakuraba, Y.; Jeong, J.; Kang, M.Y.; Kim, J.; Paek, N.C.; Choi, G. Phytochrome-interacting transcription factors PIF4 and PIF5 induce leaf senescence in Arabidopsis. Nat. Commun. 2014, 5, 4636. [CrossRef]

81. Su, M.; Huang, G.; Zhang, Q.; Wang, X.; Li, C.; Tao, Y.; Zhang, S.; Lai, J.; Yang, C.; Wang, Y. The LEA protein, ABR, is regulated by ABI5 and involved in dark-induced leaf senescence in Arabidopsis thaliana. Plant Sci. 2016, 247, 93-103. [CrossRef]

82. Gao, S.; Gao, J.; Zhu, X.; Song, Y.; Li, Z.; Ren, G.; Zhou, X.; Kuai, B. ABF2, ABF3, and ABF4 Promote ABA-Mediated Chlorophyll Degradation and Leaf Senescence by Transcriptional Activation of Chlorophyll Catabolic Genes and Senescence-Associated Genes in Arabidopsis. Mol. Plant 2016, 9, 1272-1285. [CrossRef] [PubMed]

83. Zhu, T.; Li, L.; Feng, L.; Ren, M. StABI5 involved in the regulation of chloroplast development and photosynthesis in potato. Int. J. Mol. Sci. 2020, 21, 1068. [CrossRef] [PubMed]

84. An, J.P.; Zhang, X.W.; Liu, Y.J.; Zhang, J.C.; Wang, X.F.; You, C.X.; Hao, Y.J. MdABI5 works with its interaction partners to regulate abscisic acid-mediated leaf senescence in apple. Plant J. 2021, 105, 1566-1581. [CrossRef] [PubMed]

85. Orellana, S.; Yañez, M.; Espinoza, A.; Verdugo, I.; González, E.; Ruiz-Lara, S.; Casaretto, J.A. The transcription factor SlAREB1 confers drought, salt stress tolerance and regulates biotic and abiotic stress-related genes in tomato. Plant Cell Environ. 2010, 33, 2191-2208. [CrossRef]

86. Wang, W.; Qiu, X.; Yang, Y.; Kim, H.S.; Jia, X.; Yu, H.; Kwak, S.S. Sweetpotato BZIP transcription factor IBABF4 confers tolerance to multiple abiotic stresses. Front. Plant Sci. 2019, 10, 630. [CrossRef]

87. Liao, C.J.; Lai, Z.; Lee, S.; Yun, D.J.; Mengiste, T. Arabidopsis HOOKLESS1 regulates responses to pathogens and abscisic acid through interaction with MED18 and acetylation of WRKY33 and ABI5 chromatin. Plant Cell 2016, 28, 1662-1681. [CrossRef]

88. Cui, W.; Wang, S.; Han, K.; Zheng, E.; Ji, M.; Chen, B.; Wang, X.; Chen, J.; Yan, F. Ferredoxin 1 is downregulated by the accumulation of abscisic acid in an ABI5-dependent manner to facilitate rice stripe virus infection in Nicotiana benthamiana and rice. Plant J. 2021. [CrossRef]

89. Hwang, K.; Susila, H.; Nasim, Z.; Jung, J.Y.; Ahn, J.H. Arabidopsis ABF3 and ABF4 Transcription Factors Act with the NF-YC Complex to Regulate SOC1 Expression and Mediate Drought-Accelerated Flowering. Mol. Plant 2019, 12, 489-505. [CrossRef]

90. Xiong, F.; Ren, J.J.; Yu, Q.; Wang, Y.Y.; Lu, C.C.; Kong, L.J.; Otegui, M.S.; Wang, X.L. AtU2AF65b functions in abscisic acid mediated flowering via regulating the precursor messenger RNA splicing of ABI5 and FLC in Arabidopsis. New Phytol. 2019, 223, 277-292. [CrossRef]

91. Li, S.; Chen, K.; Grierson, D. Molecular and Hormonal Mechanisms Regulating Fleshy Fruit Ripening. Cells 2021, $10,1136$. [CrossRef] [PubMed]

92. Sadka, A.; Qin, Q.; Feng, J.; Farcuh, M.; Shlizerman, L.; Zhang, Y.; Toubiana, D.; Blumwald, E. Ethylene response of plum ACC synthase 1 (ACS1) promoter is mediated through the binding site of abscisic acid insensitive 5 (ABI5). Plants 2019, 8, 117. [CrossRef] [PubMed]

93. Jia, P.; Xing, L.; Zhang, C.; Zhang, D.; Ma, J.; Zhao, C.; Han, M.; Ren, X.; An, N. MdKNOX19, a class II knotted-like transcription factor of apple, plays roles in ABA signalling/sensitivity by targeting ABI5 during organ development. Plant Sci. 2021, 302, 110701. [CrossRef]

94. Ma, Q.J.; Sun, M.H.; Lu, J.; Liu, Y.J.; Hu, D.G.; Hao, Y.J. Transcription factor AREB2 is involved in soluble sugar accumulation by activating sugar transporter and amylase genes1. Plant Physiol. 2017, 174, 2348-2362. [CrossRef]

95. Chen, J.; Li, Y.; Li, F.; Wu, Q.; Jiang, Y.; Yuan, D. Banana MaABI5 is involved in ABA-induced cold tolerance through interaction with a RING E3 ubiquitin ligase, MaC3HC4-1. Sci. Hortic. 2018, 237, 239-246. [CrossRef]

96. Casaretto, J.; Ho, T.D. The transcription factors HvABI5 and HvVP1 are required for the abscisic acid induction of gene expression in barley aleurone cells. Plant Cell 2003, 15, 271-284. [CrossRef]

97. Zou, M.; Guan, Y.; Ren, H.; Zhang, F.; Chen, F. A bZIP transcription factor, OsABI5, is involved in rice fertility and stress tolerance. Plant Mol. Biol. 2008, 66, 675-683. [CrossRef]

98. Kobayashi, F.; Maeta, E.; Terashima, A.; Takumi, S. Positive role of a wheat HvABI5 ortholog in abiotic stress response of seedlings. Physiol. Plant. 2008, 134, 74-86. [CrossRef]

99. Yan, F.; Deng, W.; Wang, X.; Yang, C.; Li, Z. Maize (Zea mays L.) homologue of ABA-insensitive (ABI) 5 gene plays a negative regulatory role in abiotic stresses response. Plant Growth Regul. 2012, 68, 383-393. [CrossRef]

100. Xu, D.B.; Gao, S.Q.; Ma, Y.Z.; Xu, Z.S.; Zhao, C.P.; Tang, Y.M.; Li, X.Y.; Li, L.C.; Chen, Y.F.; Chen, M. ABI-like transcription factor gene TaABL1 from wheat improves multiple abiotic stress tolerances in transgenic plants. Funct. Integr. Genomics 2014, 14, 717-730. [CrossRef]

101. Wang, J.; Li, Q.; Mao, X.; Li, A.; Jing, R. Wheat transcription factor TaAREB3 participates in drought and freezing tolerances in Arabidopsis. Int. J. Biol. Sci. 2016, 12, 257-269. [CrossRef] [PubMed]

102. Kagaya, Y.; Hobo, T.; Murata, M.; Ban, A.; Hattori, T. Abscisic acid-induced transcription is mediated by phosphorylation of an abscisic acid response element binding factor, TRAB1. Plant Cell 2002, 14, 3177-3189. [CrossRef] 
103. Lu, G.; Gao, C.; Zheng, X.; Han, B. Identification of OsbZIP72 as a positive regulator of ABA response and drought tolerance in rice. Planta 2009, 229, 605-615. [CrossRef]

104. Hossain, M.A.; Lee, Y.; Cho, J.I.; Ahn, C.H.; Lee, S.K.; Jeon, J.S.; Kang, H.; Lee, C.H.; An, G.; Park, P.B. The bZIP transcription factor OsABF1 is an ABA responsive element binding factor that enhances abiotic stress signaling in rice. Plant Mol. Biol. 2010, 72, 557-566. [CrossRef]

105. Hossain, M.A.; Cho, J.I.; Han, M.; Ahn, C.H.; Jeon, J.S.; An, G.; Park, P.B. The ABRE-binding bZIP transcription factor OsABF2 is a positive regulator of abiotic stress and ABA signaling in rice. J. Plant Physiol. 2010, 167, 1512-1520. [CrossRef]

106. Yang, X.; Yang, Y.N.; Xue, L.J.; Zou, M.J.; Liu, J.Y.; Chen, F.; Xue, H.W. Rice ABI5-like1 regulates abscisic acid and auxin responses by affecting the expression of ABRE-containing genes. Plant Physiol. 2011, 156, 1397-1409. [CrossRef] [PubMed]

107. Zhang, X.; Wang, L.; Meng, H.; Wen, H.; Fan, Y.; Zhao, J. Maize ABP9 enhances tolerance to multiple stresses in transgenic Arabidopsis by modulating ABA signaling and cellular levels of reactive oxygen species. Plant Mol. Biol. 2011, 75, 365-378. [CrossRef] [PubMed]

108. Cao, X.Y.; Chen, M.; Xu, Z.S.; Chen, Y.F.; Li, L.C.; Yu, Y.H.; Liu, Y.N.; Ma, Y.Z. Isolation and Functional Analysis of the bZIP Transcription Factor Gene TaABP1 from a Chinese Wheat Landrace. J. Integr. Agric. 2012, 11, 1580-1591. [CrossRef]

109. Johnson, R.R.; Shin, M.; Shen, J.Q. The wheat PKABA1-interacting factor TaABF1 mediates both abscisic acid-suppressed and abscisic acid-induced gene expression in bombarded aleurone cells. Plant Mol. Biol. 2008, 68, 93-103. [CrossRef] [PubMed]

110. Schoonheim, P.J.; Costa Pereira, D.D.; De Boer, A.H. Dual role for 14-3-3 proteins and ABF transcription factors in gibberellic acid and abscisic acid signalling in barley (Hordeum vulgare) aleurone cells. Plant Cell Environ. 2009, 32, 439-447. [CrossRef]

111. Cantoro, R.; Crocco, C.D.; Benech-Arnold, R.L.; Rodríguez, M.V. In vitro binding of Sorghum bicolor transcription factors ABI4 and ABI5 to a conserved region of a GA 2-OXIDASE promoter: Possible role of this interaction in the expression of seed dormancy. J. Exp. Bot. 2013, 64, 5721-5735. [CrossRef] [PubMed]

112. Harris, L.J.; Martinez, S.A.; Keyser, B.R.; Dyer, W.E.; Johnson, R.R. Functional analysis of TaABF1 during abscisic acid and gibberellin signalling in aleurone cells of cereal grains. Seed Sci. Res. 2013, 23, 89-98. [CrossRef]

113. Ishibashi, Y.; Aoki, N.; Kasa, S.; Sakamoto, M.; Kai, K.; Tomokiyo, R.; Watabe, G.; Yuasa, T.; Iwaya-Inoue, M. The interrelationship between abscisic acid and reactive oxygen species plays a key role in barley seed dormancy and germination. Front. Plant Sci. 2017, 8, 275. [CrossRef]

114. Collin, A.; Daszkowska-Golec, A.; Kurowska, M.; Szarejko, I. Barley ABI5 (Abscisic Acid INSENSITIVE 5) Is Involved in Abscisic Acid-Dependent Drought Response. Front. Plant Sci. 2020, 11, 1138. [CrossRef] [PubMed]

115. Tang, N.; Zhang, H.; Li, X.; Xiao, J.; Xiong, L. Constitutive activation of transcription factor OsbZIP46 improves drought tolerance in rice. Plant Physiol. 2012, 158, 1755-1768. [CrossRef] [PubMed]

116. Piao, W.; Kim, S.H.; Lee, B.D.; An, G.; Sakuraba, Y.; Paek, N.C. Rice transcription factor OsMYB102 delays leaf senescence by down-regulating abscisic acid accumulation and signaling. J. Exp. Bot. 2019, 70, 2699-2715. [CrossRef]

117. Liu, Y.H.; Jiang, M.; Li, R.Q.; Huang, J.Z.; Shu, Q.Y. Oskeap1 interacts with osabi5 and its downregulation increases the transcription of osabi5 and the aba response genes in germinating rice seeds. Plants 2021, 10, 527. [CrossRef]

118. Rodríguez, M.V.; Mendiondo, G.M.; Maskin, L.; Gudesblat, G.E.; Iusem, N.D.; Benech-Arnold, R.L. Expression of ABA signalling genes and ABI5 protein levels in imbibed Sorghum bicolor caryopses with contrasting dormancy and at different developmental stages. Ann. Bot. 2009, 104, 975-985. [CrossRef]

119. Utsugi, S.; Ashikawa, I.; Nakamura, S.; Shibasaka, M. TaABI5, a wheat homolog of Arabidopsis thaliana ABA insensitive 5, controls seed germination. J. Plant Res. 2020, 133, 245-256. [CrossRef]

120. Zhang, Y.; Sun, Q.; Zhang, C.; Hao, G.; Wang, C.; Dirk, L.M.A.; Downie, A.B.; Zhao, T. Maize VIVIPAROUS1 Interacts with ABA INSENSITIVE5 to Regulate GALACTINOL SYNTHASE2 Expression Controlling Seed Raffinose Accumulation. J. Agric. Food Chem. 2019, 67, 4214-4223. [CrossRef] [PubMed]

121. Zhou, K.; Yang, J.; Wang, Z.X.; Wang, J.R. Sequence analysis and expression profiles of TaABI5, a pre-harvest sprouting resistance gene in wheat. Genes Genom. 2017, 39, 161-171. [CrossRef]

122. Wang, X.; Guo, C.; Peng, J.; Li, C.; Wan, F.; Zhang, S.; Zhou, Y.; Yan, Y.; Qi, L.; Sun, K.; et al. ABRE-BINDING FACTORS play a role in the feedback regulation of ABA signaling by mediating rapid ABA induction of ABA co-receptor genes. New Phytol. 2019, 221, 341-355. [CrossRef]

123. Zhao, H.; Nie, K.; Zhou, H.; Yan, X.; Zhan, Q.; Zheng, Y.; Song, C.P. ABI5 modulates seed germination via feedback regulation of the expression of the PYR/PYL/RCAR ABA receptor genes. New Phytol. 2020, 228, 596-608. [CrossRef] [PubMed]

124. Pan, W.; Zheng, P.; Zhang, C.; Wang, W.; Li, Y.; Fan, T.; Liu, Y.; Cao, S. The effect of ABRE BINDING FACTOR 4-mediated FYVE1 on salt stress tolerance in Arabidopsis. Plant Sci. 2020, 296, 110489. [CrossRef]

125. Belda-Palazon, B.; Rodriguez, L.; Fernandez, M.A.; Castillo, M.C.; Anderson, E.M.; Gao, C.; Gonzalez-Guzman, M.; Peirats-Llobet, M.; Zhao, Q.; De Winne, N.; et al. FYVE1/FREE1 interacts with the PYL4 ABA receptor and mediates its delivery to the vacuolar degradation pathway. Plant Cell 2016, 28, 2291-2311. [CrossRef]

126. Li, H.; Li, Y.; Zhao, Q.; Li, T.; Wei, J.; Li, B.; Shen, W.; Yang, C.; Zeng, Y.; Rodriguez, P.L.; et al. The plant ESCRT component FREE1 shuttles to the nucleus to attenuate abscisic acid signalling. Nat. Plants 2019, 5, 512-524. [CrossRef] [PubMed]

127. Zong, W.; Tang, N.; Yang, J.; Peng, L.; Ma, S.; Xu, Y.; Li, G.; Xiong, L. Feedback regulation of ABA signaling and biosynthesis by a bZIP transcription factor targets drought-resistance-related genes. Plant Physiol. 2016, 171, 2810-2825. [CrossRef] [PubMed] 
128. Kang, J.Y.; Choi, H.I.; Im, M.Y.; Soo, Y.K. Arabidopsis basic leucine zipper proteins that mediate stress-responsive abscisic acid signaling. Plant Cell 2002, 14, 343-357. [CrossRef] [PubMed]

129. Kim, J.B.; Kang, J.Y.; Soo, Y.K. Over-expression of a transcription factor regulating ABA-responsive gene expression confers multiple stress tolerance. Plant Biotechnol. J. 2004, 2, 459-466. [CrossRef]

130. Oh, S.J.; Sang, I.S.; Youn, S.K.; Jang, H.J.; Soo, Y.K.; Kim, M.; Kim, Y.K.; Baek, H.N.; Kim, J.K. Arabidopsis CBF3/DREB1A and ABF3 in transgenic rice increased tolerance to abiotic stress without stunting growth. Plant Physiol. 2005, 138, 341-351. [CrossRef] [PubMed]

131. Barbosa, E.G.G.; Leite, J.P.; Marin, S.R.R.; Marinho, J.P.; de Fátima Corrêa Carvalho, J.; Fuganti-Pagliarini, R.; Farias, J.R.B.; Neumaier, N.; Marcelino-Guimarães, F.C.; de Oliveira, M.C.N.; et al. Overexpression of the ABA-Dependent AREB1 Transcription Factor from Arabidopsis thaliana Improves Soybean Tolerance to Water Deficit. Plant Mol. Biol. Rep. 2013, 31, 719-730. [CrossRef]

132. Mittal, A.; Gampala, S.S.L.; Ritchie, G.L.; Payton, P.; Burke, J.J.; Rock, C.D. Related to ABA-Insensitive3(ABI3)/Viviparous1 and AtABI5 transcription factor coexpression in cotton enhances drought stress adaptation. Plant Biotechnol. J. 2014, 12, 578-589. [CrossRef] [PubMed]

133. Muñiz García, M.N.; Cortelezzi, J.I.; Fumagalli, M.; Capiati, D.A. Expression of the Arabidopsis ABF4 gene in potato increases tuber yield, improves tuber quality and enhances salt and drought tolerance. Plant Mol. Biol. 2018, 98, 137-152. [CrossRef]

134. Wang, Z.; Su, G.; Li, M.; Ke, Q.; Kim, S.Y.; Li, H.; Huang, J.; Xu, B.; Deng, X.P.; Kwak, S.S. Overexpressing Arabidopsis ABF3 increases tolerance to multiple abiotic stresses and reduces leaf size in alfalfa. Plant Physiol. Biochem. 2016, 109, 199-208. [CrossRef]

135. Na, J.K.; Metzger, J.D. Guard-cell-specific expression of Arabidopsis ABF4 improves drought tolerance of tomato and tobacco. Mol. Breed. 2017, 37, 154. [CrossRef]

136. Zhao, B.Y.; Hu, Y.F.; Li, J.J.; Yao, X.; Liu, K.-D. BnaABF2, a bZIP transcription factor from rapeseed (Brassica napus L.), enhances drought and salt tolerance in transgenic Arabidopsis. Bot. Stud. 2016, 57, 12. [CrossRef]

137. Liu, J.; Chu, J.; Ma, C.; Jiang, Y.; Ma, Y.; Xiong, J.; Cheng, Z.M. Overexpression of an ABA-dependent grapevine bZIP transcription factor, VvABF2, enhances osmotic stress in Arabidopsis. Plant Cell Rep. 2019, 38, 587-596. [CrossRef] [PubMed]

138. Wang, C.; Lu, G.; Hao, Y.; Guo, H.; Guo, Y.; Zhao, J.; Cheng, H. ABP9, a maize bZIP transcription factor, enhances tolerance to salt and drought in transgenic cotton. Planta 2017, 246, 453-469. [CrossRef] 